\title{
The role of focus intonation in implicature computation: a comparison with only and also
}

\author{
Nicole Gotzner ${ }^{1}$ (1) \\ Published online: 18 May 2019 \\ (C) The Author(s) 2019
}

\begin{abstract}
The function of focus is to activate alternatives, and these activated alternatives are used to compute the corresponding inferences of an utterance. The experimental research reported here investigates the role of focus intonation in inference computation and its interplay with the overt focus particles only and also. In particular, I compare the mechanisms underlying the computation of exhaustivity implicatures, assertions, and additive presuppositions. A memory delay experiment revealed that contrastive intonation $\left(\mathrm{L}+\mathrm{H}^{*}\right)$ makes an exhaustive interpretation equally available as overt only. A second experiment showed that in immediate processing, the implicature in bare focus conditions is delayed relative to the inferences associated with only and also. The findings thus indicate that $\mathrm{L}+\mathrm{H}^{*}$ accents do not conventionally encode an exhaustive meaning, but encourage implicature computation by (i) making relevant alternatives salient and (ii) providing a strong cue that an inference should be derived.
\end{abstract}

Keywords Focus intonation · Focus particles · Implicatures · Exhaustivity · Presuppositions

\section{Introduction}

Theories of focus and implicature posit a strong connection between focus, intonation, and the inferences listeners derive from an utterance (see especially Groenendijk and Stokhof 1984; Rooth 1992; van Rooij and Schulz 2004; Schulz and van Rooij 2006; Chierchia 2013). Consider the example shown in (1), taken from Rooth (1992). The focus of an utterance typically bears the greatest prosodic prominence, and depending on where the focal stress falls, as indicated by subscript $\mathrm{F}$, different inferences are triggered.

Nicole Gotzner

gotzner@leibniz-zas.de

1 Leibniz-Zentrum Allgemeine Sprachwissenschaft (ZAS), Schützenstr. 18, 10117 Berlin, Germany 
(1) a. $[\mathrm{Carl}]_{F}$ likes herring.

b. Carl likes [herring $]_{F}$.

Utterance (1a) evokes alternatives to the subject and implicates that Carl likes herring, in contrast to other salient individuals in the discourse. Utterance (1b), on the other hand, evokes alternatives to the object and implicates that Carl likes herring but no other types of food or fish.

The standard theory of focus assumes that its function is to introduce a set of alternatives (see Rooth 1985, 1992). What is not part of the semantics of focus is the exclusion of alternatives, for example the inference that no other person likes herring that can be derived from (1a). This communicated meaning, referred to as an implicature, is based on additional enrichment procedures. For instance, listeners may reason that if the speaker had meant to communicate that other people like herring as well, he would have done so (see Grice 1975 for a standard theory of implicatures). Similarly, in (1b) the speaker did not mention any alternatives to herring. Since no mention of other alternatives was made, listeners infer that the statement does not hold for the alternatives under consideration. Hence, the function of focus is to provide the alternatives which are used to derive the corresponding implicatures of an utterance.

Recent psycholinguistic work has shown that focus intonation (i) activates a set of alternatives in online processsing (Braun and Tagliapietra 2010; Gotzner et al. 2013; Husband and Ferreira 2016) and (ii) facilitates implicature generation (Chevallier et al. 2008; Schwarz et al. 2008; Tomlinson et al. 2017). However, little is known about the exact mechanisms that underpin the effects of focus intonation on implicature computation. One possibility is that focus intonation facilitates the activation of alternatives and when alternatives are made salient in this way, implicature computation is more frequent and faster. An alternative possibility is that focus intonation affects the processes related to the implicature computation algorithm itself, for example biasing listeners to derive the implicature. Finally, a third possibility is that focus intonation has an impact on both processes, the activation of alternatives and the computation of implicatures.

The primary goal of this study is to find out which mechanisms focus intonation affects by looking at two competing models and the computational stages at which focus may play a role. To this end, the role of focus intonation in implicature computation is compared with the computation of the exhaustive assertion associated with the focus particle only and the additive presupposition triggered by also. First, I present the theoretical and empirical background to this research. In particular, I discuss how focus is realized in spoken language (in languages like English and German). Then, I outline two competing accounts of implicature computation and how the role of focus intonation can be implemented in these accounts. Finally, I turn to previous research investigating the role of focus intonation in alternative activation, implicature processing, and the inferences associated with focus particles. 


\section{Theoretical background}

\subsection{Focus and intonation}

According to the standard theory of focus, known as alternative semantics, the primary function of focus is to introduce a set of alternatives (Rooth 1985, 1992). Consider an utterance like (2a), Carl likes herring, with focus on Carl. The effect of focus is that in addition to (2b), the ordinary semantic value $\llbracket \cdot \rrbracket^{o},(2 \mathrm{c})$, the so-called focus semantic value $\llbracket \cdot \rrbracket^{f}$ is computed:
a. $[\mathrm{Carl}]_{F}$ likes herring.
b. Ordinary value $\llbracket \cdot \rrbracket^{o}$ : like (Carl, herring)
c. Focus semantic value $\llbracket \cdot \rrbracket^{f}$ : like (x|x $\in E$, herring), where $E$ is the domain of individuals

For our example sentence (2a), the intuition is that the focus on Carl evokes alternative individuals who might like herring. This alternative set is derived by replacing the focused element with other suitable elements of the same semantic type. In example (2a), other individuals can be substituted for the variable $x$ in the sentence frame ' $x$ likes herring'. In theory, any element that matches the semantic type of the focused element is part of the alternative set, but the context determines which alternatives are relevant.

Alternative semantics is a formal algorithm to derive the interpretational effects of focus, but Rooth remains neutral about the question how exactly focus is realized in spoken language. In intonation languages like English and German, focus is usually marked by a pitch accent (in auditory speech). There is, however, an open theoretical debate whether intonational focus is reserved to specific accent types or intonational contours (e.g., Rochemont 1986; Pierrehumbert and Hirschberg 1990; Selkirk 2002; Katz and Selkirk 2011). Work in the domain of intonational phonology, in particular Pierrehumbert (1980), proposes a distinction between a simplex $\mathrm{H}^{*}$ pitch accent and a complex $\mathrm{L}+\mathrm{H}^{*}$ accent. While the former consists of a single high target on the accented syllable, the latter accent type starts with a low initial target followed by a steep rise to a high target. According to Pierrehumbert and Hirschberg (1990), these two accent types are associated with distinct categorical meanings: the $\mathrm{H}^{*}$ accent signals new, non-contrastive information and the $\mathrm{L}+\mathrm{H}^{*}$ a contrastive or corrective interpretation (see Grice and Baumann 2002; Grice et al. 2005 for a similar proposal concerning German intonation). Following this view, intonation could conventionally encode information states such as 'new', 'given', and 'contrast'. Further, different accent types have been assumed to indicate information concerning the speaker's epistemic state (see especially Ward and Hirschberg 1985; Pierrehumbert and Hirschberg 1990).

Some evidence that listeners and speakers distinguish $\mathrm{H}^{*}$ and $\mathrm{L}+\mathrm{H}^{*}$ accents has been found in production and perception experiments by Alter et al. (2001), Selkirk (2002), Ito et al. (2004), and Krahmer and Swerts (2001), amongst others. However, the question whether the two accent types form discrete categories or are variants of the same pitch accent is a matter of ongoing debate (see for example Krahmer and Swerts 
2001; Wagner and Watson 2010 for an overview). Specifically, it is unclear whether the difference is realized by accent type (i.e., a categorical distinction) or rather by gradual prosodic differences (as found for example by Bartels and Kingston 1994). Concerning the corresponding interpretation, $\mathrm{H}^{*}$ and $\mathrm{L}+\mathrm{H}^{*}$ accents might vary only in the prominence/salience or size of the alternative set (see for example Watson et al. 2008; Calhoun 2009), rather than representing different types of focus. Yet independent of the exact theoretical status, prosodic studies indicate that contrastive accents have a higher pitch excursion, longer duration, and greater intensity than non-contrastive accents (e.g., Bartels and Kingston 1994; Selkirk 2002; Baumann et al. 2006; Katz and Selkirk 2011). Perception studies further show that contrastively-accented constituents are perceived as more prominent and contrastive than constituents carrying non-contrastive stress (i.e., either the alternatives are relatively more salient or the interpretation is more likely to be corrective: e.g., Bartels and Kingston 1994; Krahmer and Swerts 2001; Alter et al. 2001; Ito et al. 2004; Ito and Speer 2008; Watson et al. 2008).

In the following, I will use $\mathrm{H}^{*}$ and $\mathrm{L}+\mathrm{H}^{*}$ as labels for the two accent types (in line with the TOBI labeling system, see Silverman et al. 1992 for English and Grice and Baumann 2002 for German), without implying any particular a priori theoretical account of the distinction. The crucial point is that listeners distinguish the two accent types, as we will see. Later, I will discuss what the current results imply concerning the nature of the distinction.

\subsection{Models of implicature computation}

Theories of intonational phonology provide a description of the pragmatic function of different pitch accents but not a formal model of the underlying reasoning steps. In principle, a contrastive/exhaustive meaning could be attached to $\mathrm{L}+\mathrm{H}^{*}$ accents directly, but this supposes that pitch accents are always interpreted in the same way in different contexts. Alternatively, exhaustivity could be derived as a pragmatic inference. In formal semantics and pragmatics, precise models have been developed for the computation of pragmatic inferences. There has been considerable debate as to the nature of implicatures, especially surrounding the question whether implicatures are genuinely pragmatic in nature (i.e., based on reasoning procedures) or rather part of semantic meaning derivation (see Sauerland 2012 for an overview). In the following, I focus on the questions of (i) which computational steps are assumed by different models of implicature and (ii) which role is assigned to intonational focus.

Both pragmatic and semantic accounts of implicature have taken alternative semantics and exhaustivity as the basis for a theory of implicature. The underlying intuition is that implicatures arise from the negation of certain relevant alternatives, similar to the meaning conveyed by only. Compare the utterances (3a) (reprinted from above), $(3 b)$, and (3c).
a. $[\mathrm{Carl}]_{F}$ likes herring.
b. Sue likes herring.
c. Only $[\mathrm{Carl}]_{F}$ likes herring. 


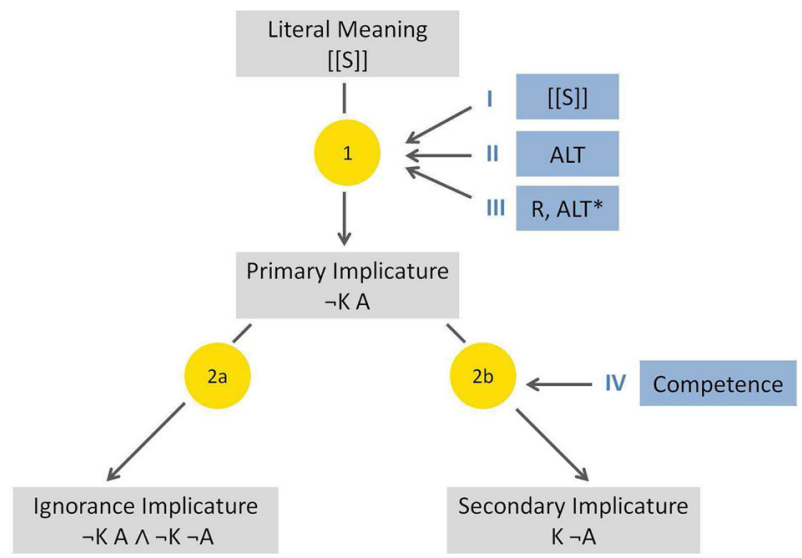

Fig. 1 Processing steps involved in implicature computation according to pragmatic accounts (figure adapted from Chemla and Singh 2014)

Sentence (3a) is typically understood such that Carl but no other salient individual in the discourse likes herring. The standard pragmatic account of implicatures (Grice 1975) derives this inference by a set of conversational maxims which both speakers and listeners adhere to. Specifically, the listener reasons about alternative utterances that could have been used, such as (3b), Sue likes herring. However, since the speaker did not utter this alternative, the listener concludes that it must be false. Hence, the conveyed meaning is akin to (3c), Only Carl likes herring, except that the exhaustive meaning of only is not cancelable.

Pragmatic models Now let us turn to sketching a precise model of implicature computation. The following figures were adapted from Chemla and Singh (2014) with some modifications. Stages of inference computation are numbered with Arabic numerals and intermediate steps that make reference to semantic and pragmatic computations outside of the implicature computation mechanism are numbered with Roman numerals. Figure 1 shows the computational steps postulated by pragmatic accounts of implicature. According to pragmatic accounts, listeners first derive the literal meaning of an utterance. Based on the literal meaning, a so-called primary implicature is drawn, namely that the speaker is not certain about the truth of stronger alternatives ( $\neg \mathrm{K} \mathrm{A}$ ) (with K representing a knowledge operator, see Sauerland 2004 and Schulz and van Rooij 2006). For example at stage (1), the listener concludes about sentence (3a) that Carl likes herring and that the speaker does not know whether other relevant individuals like herring. There are three intermediate stages listeners need to compute in order to arrive at this conclusion: (I) the semantic meaning (e.g., like (Carl, herring)), (II) the set of grammatical alternatives ALT that results from replacing the implicature trigger with alternatives/scale-mates (e.g., like (x|x $\in E$, herring)), and (III) the actual alternatives ALT*. The actual alternatives serve as input to the implicature derivation mechanism and are determined by intersecting the contextually-relevant alternatives $\mathrm{R}$ with the grammatical set of alternatives. 


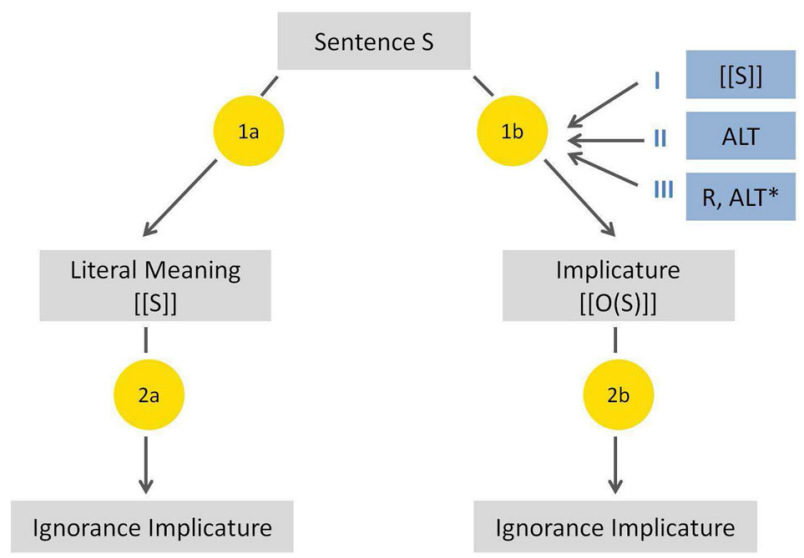

Fig. 2 Processing steps involved in implicature computation according to grammatical accounts (figure adapted from Chemla and Singh 2014)

Next, the speaker's competence (IV) is assessed, that is, whether or not s/he has knowledge of the state of the world. If the speaker is competent, the listener derives a secondary implicature $(2 \mathrm{~b})$ that the speaker is certain that stronger alternatives are false (K $\neg$ A; e.g. van Rooij and Schulz 2004; Schulz and van Rooij 2006). If, however, the speaker is not competent, the listener derives an ignorance inference that the speaker knows neither the truth nor the falsity of stronger alternatives $(\neg \mathrm{K} A \wedge \neg \mathrm{K} \neg \mathrm{A})$.

Now let us briefly discuss the role of focus in a precise formalization of a pragmatic account. van Rooij and Schulz (2004) model implicatures based on Groenendijk and Stokhof's (1984) theory of exhaustive answers to questions. They assume that exhaustive interpretation is sensitive to the dynamic semantics of the utterance and what the interpreter is interested in. Hence, grammar and pragmatics interact such that no inferences will be drawn about contextually irrelevant alternatives (see Schulz and van Rooij 2006 for concrete examples). The theory does not explicitly model the role of focus intonation, but it is possible to imagine at which candidate stages focus could play a role. If one assumes that by using certain intonational contours speakers indicate their epistemic state, focus intonation may affect the assessment of the speaker's certainty/knowledge at stage (IV) (see Pierrehumbert and Hirschberg 1990; Tomlinson et al. 2017). It is also possible to amend the model such that at stage (II) focus may help determine grammatical alternatives and at stage (III) it may signal which alternatives are relevant for the present purpose of conversation.

Grammatical models Figure 2 shows the computational steps according to grammatical accounts of implicature. In this model, there is ambiguity from the start between two parses, the literal reading and the implicature reading. Thus, the listener needs to make a decision about which reading to adopt based on contextual considerations. The same intermediate stages need to be computed: (I) the literal meaning, (II) the grammatical alternatives ALT, and (III) the actual alternatives ALT* that result when ALT is intersected with the contextually-relevant alternatives R. Hence, again pragmatic considerations impact the choice of alternatives, as well as the appropriateness 
of different readings. However, now the implicature algorithm itself is a grammatical operation: the insertion of a covert only operator. The result of applying covert only in step (1b) is that the set of actual alternatives is negated. The idea is that this operation is akin to the effect of overt only, except that the latter does not involve ambiguity between two parses. Beyond the literal and implicature readings, ignorance implicatures are computed in a second step, (2a) or (2b), respectively.

Grammatical accounts differ in their assumptions about the nature of alternatives and whether the application of exhaustivity operators is obligatory. Chierchia (2004, 2006) replaces focus alternatives with scalar alternatives determined by the specialized mechanism of Horn scales (Horn 1976). Fox and Katzir (2011), on the other hand, provide a unified theory for focus alternatives and the alternatives used to derive scalar implicatures, arguing that both are determined based on three substitution sources: (i) the lexicon, (ii) the context, and (iii) sub-constituents of the utterance. In the most recent version of a grammatical account, Chierchia (2013) explicitly models the role of focus in implicature computation. He postulates that focus activates alternatives for scalar implicature and that active alternatives have to be consumed by a covert operator like silent only (if no other overt operator is present in the structure). That is, if no other operator consumes activated alternatives, silent exhaustification is obligatory. If alternatives are consumed by an operator, they are no longer available for the derivation.

\section{Previous research}

The following section presents the state of the art of experimental research on the processing of alternatives and implicatures. First I discuss the role of intonation and overt focus operators in alternative activation. Then I will turn to the processing of implicatures and how intonation affects this process.

\subsection{Alternative activation}

Recent work in psycholinguistics has employed priming paradigms to test the assumption that intonational focus activates a set of alternatives. These studies have compared the impact of the contrastive $\mathrm{L}+\mathrm{H}^{*}$ accent on the retrieval of alternatives to that of the more neutral $\mathrm{H}^{*}$ accent. Braun and Tagliapietra (2010) found that the $\mathrm{L}+\mathrm{H}^{*}$ accent activated alternatives to the accented item (e.g., when the word slipper was pronounced with an $\mathrm{L}+\mathrm{H}^{*}$ accent the word flip flop was activated), while the $\mathrm{H}^{*}$ accent did not cause such an effect. These results are in line with the assumption by Rooth (1992) that focus (realized with $\mathrm{L}+\mathrm{H}^{*}$ ) activates alternatives. In addition, Husband and Ferreira (2016) found evidence that the $\mathrm{L}+\mathrm{H}^{*}$ accent can help restrict the set of alternatives. Specifically, they showed that initially listeners activate a broad set of elements, but after a certain delay the $\mathrm{L}+\mathrm{H}^{*}$ accent made relevant alternatives salient. This study therefore indicates that listeners need more time to evoke alternatives and converge on the relevant ones when no set of alternatives is provided in the context. For that reason, the establishment of alternative sets might incur a processing cost or effort. 
In general, Husband and Ferreira (2016) and Gotzner et al. (2016) have argued that two mechanisms underlie the activation of alternatives: one mechanism which activates a cohort of alternatives, and a second mechanism which selects the contextuallyappropriate alternatives. The study by Gotzner et al. (2016) investigated the impact of focus particles on alternatives that are either mentioned in the context or not. The results showed that listeners activate a broad set of possible alternatives, even when a more limited set of elements is explicitly provided in the context. In addition, focus particles caused an interference effect (slower recognition times) in the retrieval of alternatives. This interference effect was presumably due to competition among members of the alternative set, since the broad set of activated alternatives had to be restricted contextually. The described cognitive mechanisms of cohort activation and competition are akin to the computation of the focus semantic value and the restricted set of alternatives as assumed by Rooth (1992).

In addition, a study by Gotzner et al. (2013) compared the effects of different accent types to focus particles. In this study, a context sentence presented listeners with a set of two alternatives. The critical sentences continued with one of these elements in subject position, where it was realized with either an $\mathrm{H}^{*}$ or an $\mathrm{L}+\mathrm{H}^{*}$ pitch accent. An example item is shown in (4). The same stimuli were used in the current study; see Sect. 4.1.1 for details.

\section{Context sentence:}

Der Richter und der Zeuge verfolgten die Beweisführung.

'The judge and witness followed the argument.'

Critical sentence:

(Nur)/(Auch) der Richter/RICHTER glaubte dem Angeklagten.

'(Only)/(Also $)^{1}$ the judge/JUDGE believed the defendant.'

Continuation sentence:

Er verkündete das Urteil.

'He announced the verdict.'

After listening to the discourse, participants' task was to indicate whether an element had been previously mentioned. The results showed that the $\mathrm{L}+\mathrm{H}^{*}$ accent facilitated the recognition of the alternative (e.g., witness) to the accented noun (e.g., judge), relative to the $\mathrm{H}^{*}$ condition. By contrast, preceding the accented noun with either the focus particle only or also slowed response times. In a follow-up study by Gotzner and Spalek (2017), this facilitatory effect disappeared when participants performed a concurrent working memory task while the interference effect of only was still present. Hence, the processing of alternatives triggered by intonational focus is more dependent on central working memory resources, while in sentences with overt only, listeners always need to consider alternatives.

In conclusion, these studies show that if a context introduces a set of only two elements, the $\mathrm{L}+\mathrm{H}^{*}$ primarily makes the single contextual alternative more salient (see also Fraundorf et al. 2010, who demonstrate such an effect in long-term memory). Focus particles, on the other hand, slow recognition times relative to the condition with L+H*. In Gotzner and Spalek (2016) and Gotzner (2017), we argued that the

\footnotetext{
${ }^{1}$ Unlike in English, also can occur in this syntactic position in German.
} 
function of intonational focus is to activate alternatives and to narrow down the set of alternatives to its relevant members. Focus particles, on the other hand, introduce an additional element of competition among the set of alternatives (which leads to additional processing costs). The likely reason is that focus particles carry additional lexical meaning components and quantify over a contextually-restricted set of alternatives.

To summarize, priming studies indicate that $\mathrm{L}+\mathrm{H}^{*}$ introduces alternatives and makes specific alternatives more salient, depending on whether (and how many) alternatives are contextually available. Concerning the comparison of the effects of focus intonation and focus particles, previous experiments suggest that the time course and/or underlying mechanisms differ for contrastive accents and focus particles (ByramWashburn 2013; Gotzner et al. 2013; Gotzner 2017). Next, I turn to previous studies investigating the processing of inferences about different kinds of alternatives.

\subsection{Implicature processing}

A large body of research has investigated the processing of scalar implicatures (e.g., Bott and Noveck 2004; Bott et al. 2012; Huang and Snedeker 2009; Tomlinson et al. 2013; Degen and Tanenhaus 2015). Scalar implicatures are a special type of conversational implicature involving lexicalized scales such as some and all. Most previous studies have investigated the processing of scalar implicatures triggered by quantifiers and have found some sort of processing cost or delay for the implicature reading of an utterance compared to its literal interpretation. For example, Bott and Noveck (2004) asked participants to verify sentences like Some elephants are mammals. On its literal interpretation, that sentence is true since some is logically consistent with the stronger quantifier all. In contrast, when listeners derive a scalar implicature that some but not all elephants are mammals, they respond FALSE, which requires more processing effort than the TRUE response. This processing cost can be reduced in certain contexts (see especially Grodner et al. 2010; Degen and Tanenhaus 2015, 2016), and it is currently unclear what it reflects (see Chemla and Singh 2014). In the following, I discuss previous evidence with respect to the different stages of implicature computation outlined in Sect. 2.2.

We saw in the last section that there is a processing cost/delay associated with the identification of contextually-relevant alternatives (Husband and Ferreira 2016; Gotzner et al. 2016; Gotzner and Spalek 2017). There is also evidence that (part of) the processing cost observed in implicature computation stems from the retrieval of alternatives. Two eye-tracking studies by Degen and Tanenhaus $(2015,2016)$ showed that the naturalness and the number of competing alternatives affects both the rate of implicature derivation and its speed. That is, the processing cost is mainly incurred when listeners entertain other alternatives to some, such as numerals.

Further, the structural characteristics of the alternative set affect the processing of an implicature, according to Chemla and Bott (2014). If listeners need to perform scalar replacements accessing the lexicon (e.g., replacing some with the stronger quantifier all), the implicature reading is delayed relative to the literal reading. On the other hand, the two readings are accessed equally when relevant alternatives are available in the linguistic context, for example in free-choice inferences and exhaustivity implicatures 
triggered by cleft sentences (Chemla and Bott 2014; van Tiel and Schaeken 2017). In sum, these studies suggest that there is a processing cost at stages (II) and (III), due to the retrieval of alternatives.

Other studies have located the cost of implicature computation in the choice between different readings. Building on the finding that scalar implicature processing involves central memory resources (De Neys and Schaeken 2007; Dieussaert et al. 2011), a study by Marty (2013) used a dual task involving a working memory component. They reasoned that the computation of implicatures involves similar steps as the processing of the assertion of only, but there is no ambiguity between two parses in the case of overt only. Their experiment showed that tapping participants' memory resources reduces the rate of scalar implicatures, whereas it does not affect the interpretation of sentences with only (only some). Therefore, Marty and Chemla concluded that the extra cost incurred in the processing of implicatures is due to the decision to derive the implicature at all, rather than the derivational process per se. This locates the processing cost in the choice between steps (1a) and (1b) in a grammatical account (see Fig. 2).

Exhaustive assertions have also been found to differ from implicatures with respect to manipulations of speaker knowledge. Bergen and Grodner (2012) compared contexts in which the speaker had partial vs. full knowledge. They found that the implicature trigger some was read more slowly in the full knowledge condition compared to the partial knowledge condition, while the subsequent sentence referring back to the complement was read faster in the full knowledge condition. On the other hand, when some was preceded by the focus particle only, the knowledge manipulation had no effect. Hence, participants only accessed information about the speaker's epistemic state when they computed an implicature, but not when the some but not all inference was asserted. This suggests that listeners devote some resources to assessing (IV), the speaker's competence in computing implicatures. In a similar vein, Breheny et al. (2013) showed that the derivation of exhaustivity implicatures is sensitive to whether the speaker is opinionated or ignorant about relevant alternatives. They take their results as evidence for a fully Gricean model that incorporates information about epistemic state in incremental processing.

Finally, a number of studies have argued that processing costs in implicature computation reflect additional resources required to derive the inference itself (see especially Bott et al. 2012; Tomlinson et al. 2013) and have taken this cost as evidence for a pragmatic model. For example, a mouse-tracking study by Tomlinson et al. (2013) showed that when participants are concurrently presented with the literal and the implicated meaning of an utterance, their mouse paths first go to the literal meaning; only later do participants correct their responses, deriving the implicature. This result indicates that listeners first seem to compute the literal meaning of an utterance before deriving its implicated meaning in a second step, which is akin to the process described by pragmatic accounts in Fig. 1. 


\subsection{Inferences triggered by intonation and focus particles}

Many previous studies show that implicature computation is costly but that processing costs can be reduced in certain contexts. One additional factor that has been found to facilitate implicature computation is focus intonation. For example, studies by Chevallier et al. (2008) and Schwarz et al. (2008) showed that stress on a lexical trigger (some or $o r$ ) increases the likelihood with which participants derive a scalar implicature. Further, focus intonation has been found to increase the derivation of exhaustivity implicatures (Onea and Beaver 2011). These studies suggest that focus plays a role in implicature computation but they leave open which mechanisms underlie the effects.

One previous mouse-tracking study by Tomlinson et al. (2017) reveals insights into the effect of focus on implicature processing. In Tomlinson et al. (2017) participants listened to sentences like Mark has a candle and had to click on a picture showing either a single object, representing the implicated meaning, or two objects, representing the literal meaning. Participants' mouse paths towards the implicated meaning were faster and more direct when they heard a sentence with an $\mathrm{L}+\mathrm{H}^{*}$ accent on the object noun phrase. In a second experiment, the $\mathrm{L}+\mathrm{H}^{*}$ created a garden path effect: participants initially favoured the implicated meaning and had to correct their response when the rest of the sentence specified a different location of the object (e.g., Mark has a candle on a shelf). This suggests that listeners derive the implicature incrementally with the $\mathrm{L}+\mathrm{H}^{*}$ accent; they do not wait until the end of the utterance to decide on the final interpretation. In sum, these findings suggest that $\mathrm{L}+\mathrm{H}^{*}$ triggers a highly prevalent implicature and facilitates the speed with which this inference is processed.

As discussed in the previous section, listeners process implicatures differently when they have to access scalar alternatives from the lexicon (Chemla and Bott 2014), highlighting the importance of testing implicatures involving different kinds of alternatives. Chevallier et al. (2008) and Schwarz et al. (2008) showed a facilitatory effect of prosody on lexicalized scales and Tomlinson et al. (2017) tested exhaustivity implicatures. However, in the Tomlinson et al. study listeners were presented with alternatives in the visual context rather than the utterance context. To derive the exhaustivity inference listeners had to consider a conjunctive statement involving the focused element and a potential alternative (e.g., Mark has a candle and a camel). On the other hand, there was a bias to favour the single-object picture since the utterance only mentioned one object. In this case, the $\mathrm{L}+\mathrm{H}^{*}$ may have facilitated the processing of the focused element. Therefore, it is an open question whether focus intonation would still have an additional effect on implicature processing when relevant alternatives are presented in the linguistic context. To gain further insights into the computational steps at which focus intonation plays a role, the current study presents listeners with a contextual set of two alternatives. Furthermore, the effect of focus intontation on implicature processing is compared to sentences with focus particles.

In a previous visual world study Schwarz (2015) compared the processing of inferences associated with different types of focus particles. In contrast to only, additive particles like too and also carry a presupposition that certain alternatives are true. For example, the sentence 'Carl also likes [herring $]_{F}$ ' presupposes that Carl likes 
Table 1 Effects of focus intonation and focus particles at different computational levels

\begin{tabular}{llll}
\hline Derivation & Focus intonation & Overt only & Overt also \\
\hline (II)/(III) ALT $^{*}$ & Facilitation & Processing cost & Processing cost \\
$(1 \mathrm{~b}) /(2 \mathrm{~b})$ Inference & Facilitation & - & - \\
$(\mathrm{IV})$ Competence & - & No effect & - \\
\hline
\end{tabular}

herring, in addition to something else. ${ }^{2}$ In the study by Schwarz (2015), participants' eye-gaze patterns indicated that listeners evaluated presuppositions more immediately than asserted content. Hence, these results indicate that the additive presupposition of also might be integrated earlier into sentence meaning than the exhaustive assertion associated with only (see also Kim 2012, who investigated only and also in on-line processing). Work by Domaneschi et al. (2014) suggests that depending on the type of presupposition trigger, different processing costs occur when the associated presuppositions are not contextually satisfied. Further, a study by Singh et al. (2015) showed that the plausibility of the context affects whether the presupposition of also is accommodated or not.

To summarize, previous studies have revealed different factors which may require processing resources in the computation of implicatures and the inferences of focus particles. Table 1 presents an overview of previous findings about the impact of focus intonation and the focus particles only and also at different computational levels: the derivation of (II)/(III) relevant alternatives, inference derivation itself-(1b) in a grammatical account and (2b) in a pragmatic account—and (IV) the assessment of the speaker's competence. Focus intonation has been found to facilitate the derivation and restriction of alternatives (Husband and Ferreira 2016; Gotzner et al. 2013) and to facilitate inference processing (Schwarz et al. 2008; Chevallier et al. 2008; Tomlinson et al. 2017). Focus particles, on the other hand, have been found to cause a processing cost in the derivation of relevant alternatives (Gotzner et al. 2013, 2016; Gotzner 2017). There is evidence that listeners integrate the presupposition of also earlier than the exhaustive assertion of only (Schwarz 2015) and that speaker knowledge does not play a role in sentences with only (Bergen and Grodner 2012). To date, no study has directly compared inference computation and the assessment of epistemic information in sentences with bare focus, exclusive, and additive focus particles.

\section{The current study}

The present study investigates the mechanisms underlying the effects of focus intonation on implicature computation as compared to the inferences associated with exclusive and additive focus particles. What we can learn from the two models detailed above and the results of previous studies is that there may be two different ways in which focal accents could affect implicature derivation. On the one hand, it could be that speakers use pitch accents to mark epistemic certainty. For this reason, listeners may be more likely to derive an implicature with contrastive pitch accents $\left(\mathrm{L}+\mathrm{H}^{*}\right)$

\footnotetext{
${ }^{2}$ Note that depending on whether the object or also itself is stressed, different association patterns arise.
} 
and/or start deriving it earlier on. On the other hand, focus prosody may primarily affect the activation (II) and the contextual restriction (III) of alternative sets. If alternatives are made salient by focus, listeners can readily feed actual alternatives into the implicature computation mechanism. This may reduce uncertainty as to whether the implicature reading or the literal reading should be adopted, since the presence of activated alternatives could make the insertion of silent only obligatory (see especially Chierchia 2013).

This leaves us with three ways, in general, in which focus may encourage implicature computation. (1) Focus intonation might help activate and restrict sets of alternatives and thereby facilitate implicature computation. (2) Focus intonation might affect the implicature generation mechanisms itself, either by increasing epistemic certainty or by encouraging insertion of silent only. (3) Focus intonation might affect both of these processes.

To decide between these possibilities, this study compares the impact of focus intonation on implicatures with that of the exhaustive assertion of only. From a theoretical perspective, the processes involved in computing these inferences are very similar. As outlined in Sect. 2.2, only involves the same computational steps as implicatures except that it does not involve ambiguity between the literal and the implicature reading. As noted in Sect. 3.2, processing costs may stem from different sources and it is unclear at which steps in the derivation these costs occur. Therefore, the current study compares inference computation at different temporal delays.

In the first experiment, a memory delay is introduced so that the listeners' final interpretation is tested. This should rule out any processing costs stemming from an ambiguity between different readings and superficial differences across conditions (e.g., the fact that the conditions with lexical particles contain an additional word). The second experiment presents alternative statements directly after exposure to the discourses. Further, participants are asked to indicate their level of certainty in interpreting the utterance. Hence, Experiment 2 focuses more on the processing stages involved in implicature computation than on the inferences associated with focus particles. In both experiments, I use the additive particle also as a control condition. Similar to only, also lexically requires a set of alternatives, but also carries a presupposition that relevant alternatives are true. Hence, participants should judge alternative statements to be true in the condition with also. The different particle conditions only, also, and no particle are fully crossed with the factor accent type involving the levels $\mathrm{H}^{*}$ and $\mathrm{L}+\mathrm{H}^{*}$.

The predictions of different views concerning the role of focus intonation are as follows. (1) If the main function of the $\mathrm{L}+\mathrm{H}^{*}$ accent is to activate alternatives, no effect on implicature processing should be observed in the bare focus conditions since relevant alternatives are present in the linguistic context (and should be highly activated at the immediate point in time). (2) If the $\mathrm{L}+\mathrm{H}^{*}$ has the additional function to signal that an inference should be derived, listeners should be biased to derive the implicature reading and the derivation of this reading should be facilitated as compared to the $\mathrm{H}^{*}$ condition. (3) If focus intonation has a dual function in activating alternatives and encouraging implicature computation, we would expect the $\mathrm{L}+\mathrm{H}^{*}$ to create a bias for an exhaustive reading both in memory and immediate processing. 
In addition, the view that the $\mathrm{L}+\mathrm{H}^{*}$ accent conventionally encodes exhaustivity/contrast predicts the same processing signature as expected in the condition with only. Further, we would expect the $\mathrm{L}+\mathrm{H}^{*}$ accent to be incompatible with additive also. Alternatively, if there is still an ambiguity between different readings, there should be a delay relative to the only condition, especially in immediate processing.

\subsection{Experiment 1}

In Experiment 1, I investigate how focus particles interact with focus intonation and what role focus intonation plays in implicature computation. Specifically, I compare the inferences triggered by $\mathrm{L}+\mathrm{H}^{*}$ accents, $\mathrm{H}^{*}$ accents, the exclusive particle only, the additive particle also, and a combination of focus operators with either type of pitch accent. Participants in Experiment 1 were presented with auditory discourses in German. In a context sentence, a contrast set with two referents was introduced (e.g., 'The judge and the witness followed the argument'). In a critical sentence, one of those referents was mentioned again carrying either an $\mathrm{H}^{*}$ accent or an $\mathrm{L}+\mathrm{H}^{*}$ accent without any preceding focus particle (e.g., 'The judge believed the defendant') or being preceded by the particle only or also (e.g., 'Only/ also the judge believed the defendant'). After participants had listened to the auditory stimuli, they performed a naturalness rating. Further, participants' memory for the inferences about the alternative mentioned in the first context sentence was tested (i.e. not the critical noun itself). After a delay of about 1.5 minutes ( 5 trials) after a given discourse, participants were presented with statements about that discourse and had to judge whether these statements were true or false regarding the content of a given story.

Experiment 1 pursues two specific research questions. First, I address the question what accent types focus particles most naturally combine with in terms of acceptability. Second, I am interested in whether listeners draw the same number of exhaustive inferences from overt only compared to an $\mathrm{L}+\mathrm{H}^{*}$ accent and whether a combination of the two leads to additive effects.

If participants interpret the discourses exhaustively, they should indicate that the statement about the mentioned alternative is false (especially in the conditions with only and the $\mathrm{L}+\mathrm{H}^{*}$ accent). In the case of the particle also, I expect participants to infer that the alternative statement is true. The stimuli do not introduce the presupposition of also explicitly. Nevertheless, listeners should be able to accommodate this presupposition (based on the findings by Singh et al. 2015). If the $\mathrm{L}+\mathrm{H}^{*}$ accent conventionally encodes contrast/exhaustivity, then the truth of alternative propositions should be inferred less often than when also is combined with $\mathrm{L}+\mathrm{H}^{*}$, or this combination may even be infelicitous.

\subsubsection{Methods}

Participants A total of 24 native speakers of German (18 female and 6 male, mean age 25.25 years, age range 20-31) were recruited from a participant pool at the Institute of Psychology of Humboldt University. In total, 25 participants participated in the study, but one of the subjects was bilingual (English as first native language) and 
was therefore excluded from further analyses. Participants were paid seven Euros in compensation. None of them reported any vision or hearing difficulties.

Materials The discourses followed the structure presented in (5). A first context sentence introduced two referents. A second, critical sentence mentioned one of the two referents again, describing an action. A third sentence continued the narrative.

(5) Context sentence:

Der Richter und der Zeuge verfolgten die Beweisführung.

'The judge and witness followed the argument.'

Critical sentence:

(Nur)/(Auch) der Richter/RICHTER glaubte dem Angeklagten.

'(Only)/(Also) the judge/JUDGE believed the defendant.'

Continuation sentence:

Er verkündete das Urteil.

'He announced the verdict.'

The experimental design fully crossed the factors particle condition and accent type, resulting in the six conditions summarized in Table 2.

In total, there were 60 critical items corresponding to the structure presented in (4). These items were taken from Gotzner et al. (2013). Participants were probed with alternative statements in the experimental items. For example, if the critical sentence was The judge believed the defendant, participants had to judge whether the alternative statement The witness believed the defendant was true or false.

Furthermore, 20 filler items with the same structure as the experimental items and another set of 40 filler items with mild pragmatic violations were added, so that participants rated a range of acceptable and less acceptable items. An example of an incoherent filler item is shown in (6). Participants were probed with general statements about the narrative in the filler items (e.g., Mary likes horses). These general statements could concern any of the three sentences and any of the characters.

(6) Marie und Josi waren im Pferdestall.

'Marie and Josi were in the horse barn.'

Marie wollte die Pferde striegeln.

'Marie wanted to groom the horses.'

Sie bereitete immer das Essen vor.

'She always prepared the food.'

Six experimental lists were created, rotating through the accent and particle conditions. To each list the 60 filler items were added, resulting in a total of 120 items per list. Each

Table 2 Overview of conditions

\begin{tabular}{llll}
\hline Accent/Particle & only & also & Bare \\
\hline $\mathrm{H}^{*}$ & Only-H* & Also-H* & $\mathrm{H}^{*}$ \\
$\mathrm{~L}+\mathrm{H}^{*}$ & Only-L+H* & Also-L+H* & $\mathrm{L}+\mathrm{H}^{*}$ \\
\hline
\end{tabular}




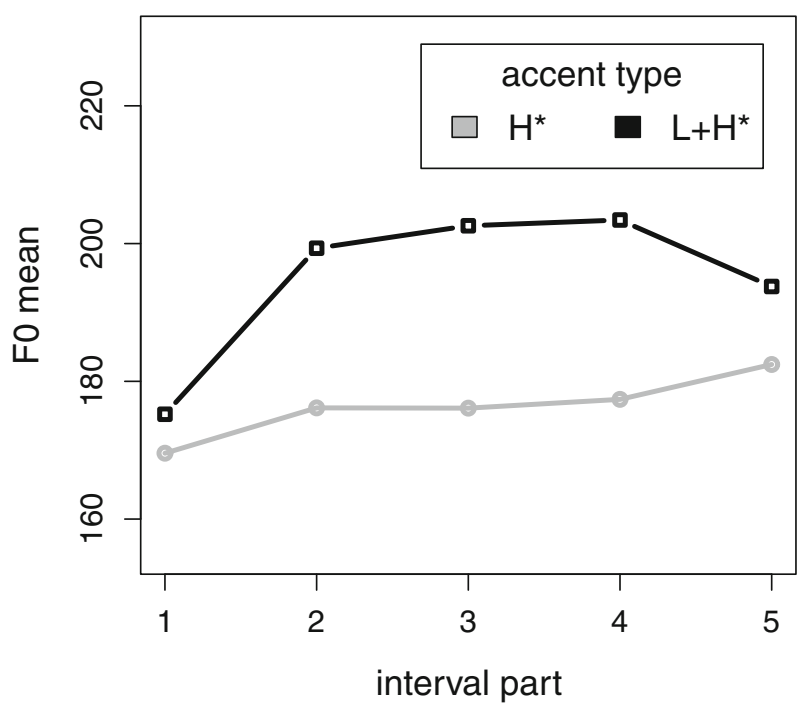

Fig. 3 Mean pitch contour of the accented syllable of the focused element (e.g., Richter) across $\mathrm{H}^{*}$ and $\mathrm{L}+\mathrm{H}^{*}$ conditions. The F0 contour was measured across five equidistant interval parts (reprinted from Gotzner et al. 2013)

participant received a different randomization with at most two filler items appearing in a row and the different experimental conditions being repeated at most twice.

Recording and acoustic measurements The critical sentences were recorded in four versions in each of the conditions $\left(\mathrm{H}^{*}, \mathrm{~L}+\mathrm{H}^{*}\right.$, only, and also). After recording, the utterances with the $\mathrm{H}^{*}$ and the $\mathrm{L}+\mathrm{H}^{*}$ accent were cross-spliced into the two utterances with only and also. Prosodic characteristics were thus held constant across different combinations of accent type and particles conditions, as well as bare accent conditions. The two accent types were not cross-spliced into one carrier sentence, since it has been argued that contrastive and non-contrastive accents might also differ in post-nuclear prosodic contours in that the former show a sudden drop in pitch contour while the latter are more sustained (see Krahmer and Swerts 2001 for experimental evidence). The fundamental frequency of the $\mathrm{L}+\mathrm{H}^{*}$ condition after the accented syllable tended to be lower than that of the $\mathrm{H}^{*}$ accent in the present stimuli, but the pitch contour of the rest of the sentence was similar. Note that both contours had a falling accent on the unaccented syllable.

Acoustic analyses were performed to compare the accented syllable of the $\mathrm{H}^{*}$ and $\mathrm{L}+\mathrm{H}^{*}$ conditions. Figure 3 shows the pitch contour of the accented syllable averaged over all items, taken from Gotzner et al. (2013). Additionally, statistical analyses were performed to compare the duration, maximum pitch, difference in intensity and alignment across accent type conditions. Table 3 summarizes the means, standard deviations and results of repeated-measures ANOVAs (within item) comparing these acoustic parameters. ${ }^{3}$ The analyses confirmed that the syllable with $\mathrm{L}+\mathrm{H}^{*}$ accent had a

\footnotetext{
3 These analyses were performed based on the 60 experimental items and 20 filler items with the same structure.
} 
Table 3 Mean acoustic parameters of the accented syllable of the focused element in the critical sentences (e.g., Richter in Example (4)). Standard errors are listed in parentheses

\begin{tabular}{lllll}
\hline Parameter & $\mathrm{H}^{*}$ & $\mathrm{~L}+\mathrm{H}^{*}$ & $\mathrm{~F}_{(1,79)}$ & $\mathrm{p}$ \\
\hline Duration (s) & $0.170 .01)$ & $0.23(0.01)$ & 129.1 & 0.001 \\
Maximum Pitch (Hz) & $195.1(4.5)$ & $226.9(6.2)$ & 19.7 & 0.001 \\
Minimum Pitch (Hz) & $161.45(3.50)$ & $170.55(2.88)$ & 6.79 & 0.01 \\
Pitch difference (Hz) & $33.6(4.5)$ & $56.3(6.2)$ & 8.5 & 0.005 \\
Point of Max (s) & $0.10(0.1)$ & $0.12(0.01)$ & 3.69 & 0.05 \\
Point of Min (s) & $0.06(0.1)$ & $0.1(0.02)$ & 13.62 & 0.001 \\
Intensity (dB) & $69.1(1.9)$ & $73.3(2.2)$ & 208 & 0.001 \\
\hline
\end{tabular}

longer duration, higher pitch excursion, greater pitch difference and intensity. Further, the pitch maximum and minimum occurred later in the $\mathrm{L}+\mathrm{H}^{*}$ accent compared to the $\mathrm{H}^{*}$ accent.

Procedure An on-screen instruction explained the structure of the experiment. The instruction told the participants that they would have to rate the naturalness of auditory stimuli and to remember the content of the stories. They were told to rate how coherent and natural the stories were on a scale from 1 (not at all acceptable) to 7 (very acceptable). Further, they were asked to indicate whether a statement was true or false regarding the content of a particular story. Participants were told that the content could be implicit in the story. Five practice trials were administered before the experiment started.

The experiment consisted of two paired tasks: (a) a rating task and (b) a truth value judgment task. Figure 4 represents the structure of one experimental block. Rating and judgment tasks interchanged every five items. After a total of five rating trials, a screen informed participants that the truth value judgment phase was about to start and they then had to judge the given statements as true or false.

Each experimental trial began with a central fixation cross displayed for $500 \mathrm{~ms}$. Participants then heard an item over headphones. Subsequently, they saw another fixation cross for $500 \mathrm{~ms}$ immediately followed by an array of numbers ranging from 1 to 7. Participants had to use a left and right button to browse through the array. By pressing a third button, they confirmed the selected number. Participants had a time window of up to $8000 \mathrm{~ms}$ for the rating. One presentation block lasted about 1.5 minutes.

In the truth value judgment phase, a fixation cross was displayed for $500 \mathrm{~ms}$ and then a blank screen was shown for $100 \mathrm{~ms}$, immediately followed by the statement. A time window of up to $10,000 \mathrm{~ms}$ was allowed for the judgment. The statement was colored green so that participants could easily identify the judgment phase. The sequence of statements corresponded to the order of presentation of the auditory stimuli. After 5 judgment trials, a screen announced the start of the next presentation/rating block.

In total, there were 24 short blocks. The entire experiment, including the postexperimental questionnaire, lasted about 45 minutes. According to the results of the 


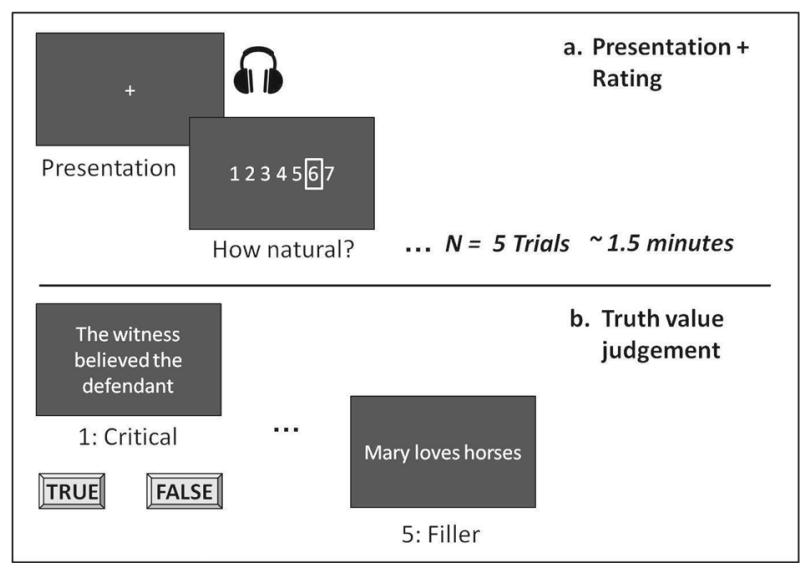

Fig. 4 Trial sequence of one experimental block (Exp. 1)

Table 4 Mean ratings across conditions

\begin{tabular}{llll}
\hline Accent/Particle & Only & Also & Bare \\
\hline $\mathrm{H}^{*}$ & 5.6 & 5.7 & 5.8 \\
$\mathrm{~L}+\mathrm{H}^{*}$ & 5.9 & 5.7 & 5.9 \\
\hline
\end{tabular}

questionnaire, none of the participants seemed to have been aware of the purpose of the experiment.

\subsubsection{Results}

Naturalness rating Table 4 shows the mean ratings across conditions. The average rating of incoherent filler items was 2.5 .

For all statistical analyses, a series of mixed models was fitted using the package lme4 in R (Bates and Sarkar 2007). I started out by fitting a model with a maximal random effects structure and iteratively removed random effects from the model if it failed to converge (Barr et al. 2013). $p$ values were extracted using the summary function of the lmerTest package (Kuznetsova et al. 2015). All factors were contrast coded. In the particle conditions, the contrast 'exhaustive' compares bare accent conditions with only conditions, while the contrast 'additive' compares the particle also with the bare and only conditions.

The final model for the naturalness ratings contained the fixed factors particle condition, probe type, their interaction, random factors for items and subjects, as well as random slopes for participants. The results of the mixed model are summarized in Table 5. The lack of significant differences indicates that the combination of the different particles with either an $\mathrm{H}^{*}$ or an $\mathrm{L}+\mathrm{H}^{*}$ accent was perceived as equally felicitous. Further, the discourses with also were felicitous even though the additive presupposition was not explicitly introduced.

Truth value judgment The mean percentages of TRUE answers from the truth value judgment task are found in Fig. 5. 
Table 5 Mixed effects model for naturalness ratings in

Experiment 1 (contrast coding)

\begin{tabular}{lclrr}
\hline & $\beta$ & $\mathrm{SE}$ & $\mathrm{t}$-value & $p$ value \\
\hline (Intercept) & 5.6713 & 0.1684 & 33.669 & \\
Accent & 0.18 & 0.153 & 1.177 & 0.244 \\
Exhaustive & -0.036 & 0.1874 & -0.192 & 0.848 \\
Additive & -0.1111 & 0.1626 & -0.684 & 0.497 \\
Accent:exhaustive & 0.296 & 0.3771 & 0.785 & 0.436 \\
Accent:additive & -0.4242 & 0.3322 & -1.277 & 0.207 \\
\hline
\end{tabular}

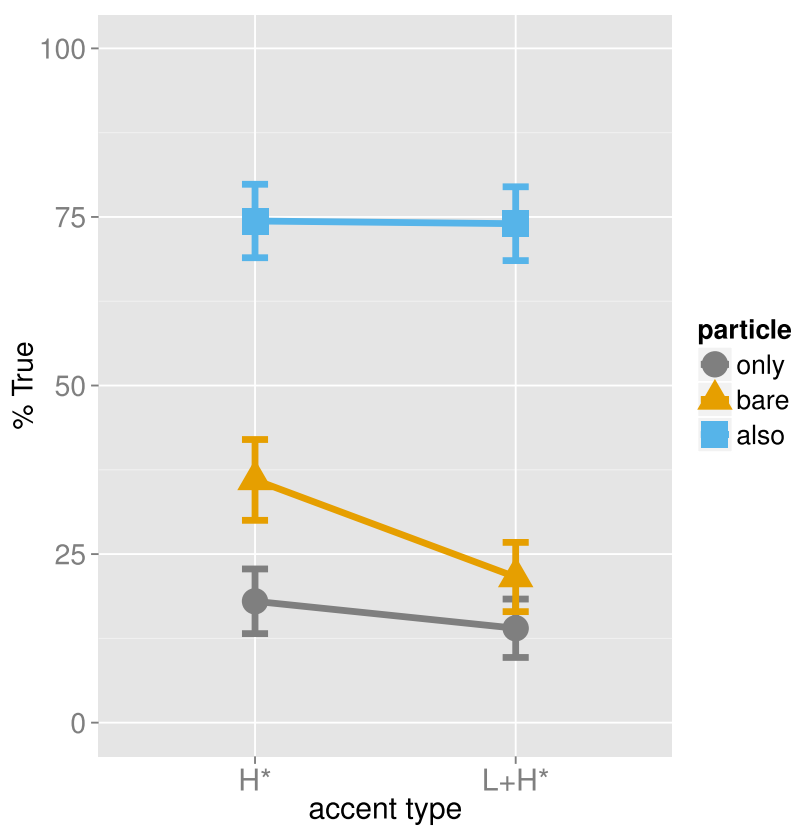

Fig. 5 Mean percent of TRUE answers across conditions in Experiment 1 (circle $=$ also, square $=$ bare, triangle $=$ only). Error bars represent $95 \%$ confidence intervals

The responses were analyzed with logit mixed effects models involving contrast coding of all factors. The results showed that the factor accent had a significant effect $(\beta=-0.0 .41, \mathrm{SE}=0.19, \mathrm{z}=-2.16, p<0.05)$, indicating that participants derived more exhaustive inferences in the condition with $\mathrm{L}+\mathrm{H}^{*}$ accent. There was also a significant difference between utterances with bare focus and exhaustive particles $(\beta=-0.82, \mathrm{SE}=0.23, \mathrm{z}=-3.5, p<0.001)$ and comparing exhaustive cases with additive particles $(\beta=2.7, \mathrm{SE}=0.2, \mathrm{z}=13.1, p<0.0001)$. Finally, there was a marginal interaction between the factors accent and additive particles $(\beta=0.68$, $\mathrm{SE}=0.4, \mathrm{z}=1.69, p=0.09$ ). The results of the mixed model are detailed in Table 6.

The specific goal of this study was to compare the differences between the bare $\mathrm{L}+\mathrm{H}^{*}$ and the condition with only. Therefore, a post hoc mixed model with the bare $\mathrm{L}+\mathrm{H}^{*}$ condition as reference level (treatment coding) was run; the results are 
Table 6 Mixed effects model for truth value judgment task in Experiment 1 (contrast coding)

\begin{tabular}{lcccc}
\hline & $\beta$ & SE & z-value & $p$ value \\
\hline (Intercept) & -0.5812 & 0.1576 & -3.688 & \\
Accent & -0.4075 & 0.1891 & -2.155 & 0.031158 \\
Exhaustive & -0.8119 & 0.2345 & -3.462 & 0.000535 \\
Additive & 2.7025 & 0.2068 & 13.071 & 0.0001 \\
Accent:exhaustive & 0.4441 & 0.4684 & 0.948 & 0.343036 \\
Accent:additive & 0.6834 & 0.4034 & 1.694 & 0.090227 \\
\hline
\end{tabular}

Table 7 Mixed effects model for RTs of expected responses in Experiment 1 (contrast coding)

\begin{tabular}{lrllr}
\hline & $\beta$ & $\mathrm{SE}$ & $\mathrm{t}$-value & $p$ value \\
\hline (Intercept) & 7.82674 & 0.04559 & 171.658 & \\
Accent & -0.01606 & 0.03653 & -0.44 & 0.662 \\
Exhaustive & -0.09136 & 0.0447 & -2.044 & 0.0459 \\
Additive & -0.01985 & 0.03926 & -0.506 & 0.6152 \\
Accent:exhaustive & 0.13687 & 0.08938 & 1.531 & 0.1316 \\
Accent:additive & 0.11043 & 0.07836 & 1.409 & 0.1646 \\
\hline
\end{tabular}

Only RTs for expected responses were included in the model $\left(\right.$ also- $\mathrm{H}^{*}$, also-L+H* $=\mathrm{TRUE}$; $\mathrm{H}^{*}, \mathrm{~L}_{+} \mathrm{H}^{*}$, only-H*, only-L+H* = FALSE)

summarized in Table 14 of 'Appendix A'. This model showed that participants gave significantly more FALSE responses in the bare $\mathrm{L}+\mathrm{H}^{*}$ condition compared to the $\mathrm{H}^{*}$ condition $(\beta=0.86, \mathrm{SE}=0.32, \mathrm{z}=2.7, p<0.001)$. The $\mathrm{L}+\mathrm{H}^{*}$ condition, however, did not differ from the only-L+H* condition $(p=0.13)$, and there was no interaction with the accent type ( $p=0.34)$.

Further, the reaction times for expected answers were compared. For the conditions with $\mathrm{H}^{*}, \mathrm{~L}+\mathrm{H}^{*}$, and the respective only-conditions, trials in which participants responded FALSE were analysed. In the conditions with also, those trials in which participants responded TRUE were analysed. This resulted in a subset excluding $23.6 \%$ of the entire dataset. In addition, all outliers more than two standard deviations from a participant's mean in a given focus condition were excluded (3.4\%). Figure 6 displays the mean reaction times across conditions (Table 7).

First, a linear mixed model with the log-RTs and contrast coding of all factors was fitted. The model showed that there was no main effect of accent type. In the conditions with exhaustive only reaction times were faster than in the bare condition $(\beta=-0.09$, $\mathrm{SE}=0.045, \mathrm{t}=-2.04, p<0.05$ ), while the exhaustive cases did not differ from additive ones in terms of response speed. No significant interaction between accent type and particle conditions was found. The results of the mixed model are detailed in Table 14.

To compare the difference between the $\mathrm{L}+\mathrm{H}^{*}$ condition and the conditions with only, another model with treatment coding was run. This model showed that participants were marginally faster at responding FALSE in the condition with $\mathrm{L}+\mathrm{H}^{*}$ compared 


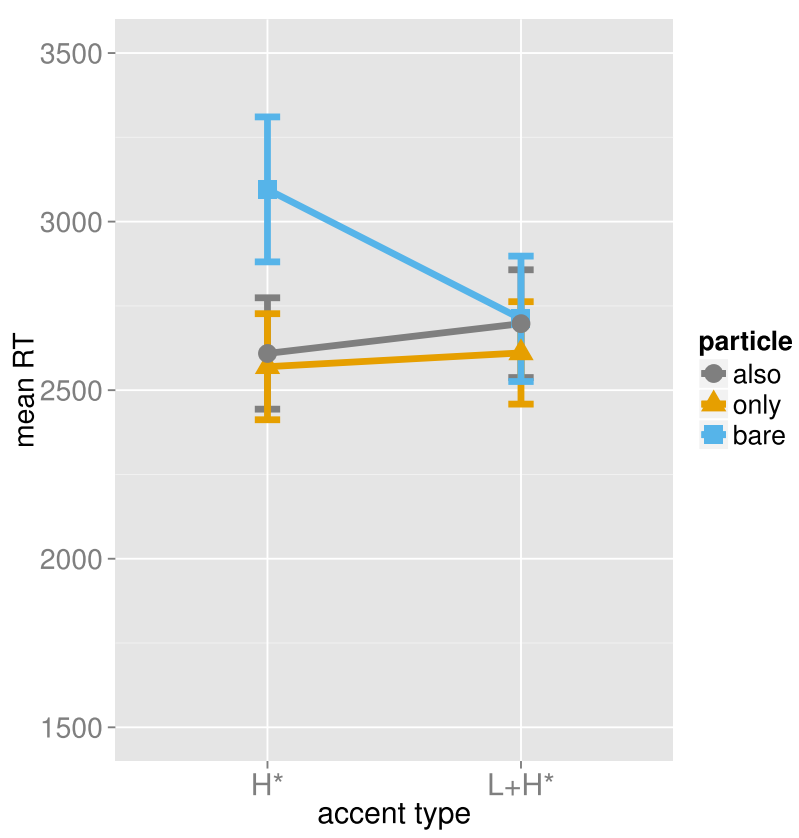

Fig. 6 Mean RT for expected response in truth value judgment task in Experiment 1 (circle $=$ also, answer TRUE; square = bare, answer FALSE; triangle = only, answer FALSE). Error bars represent $95 \%$ confidence intervals

to $\mathrm{H} *(\beta=0.12, \mathrm{SE}=0.06, \mathrm{t}=1.89, p=0.06)$. The difference between the bare $\mathrm{L}+\mathrm{H}^{*}$ condition and only was not significant $(p=0.71)$. The model is shown in Table 15 in 'Appendix A'.

\subsubsection{Discussion}

Summary of findings The rating data show that test sentences were more appropriate than incoherent filler sentences. Crucially, the use of a particular focus particle was perceived equally natural with an $\mathrm{H}^{*}$ pitch accent and an $\mathrm{L}+\mathrm{H}^{*}$ accent on the focused element (and the different bare accent types were also rated the same). This finding is in line with a study by Sudhoff (2010) in suggesting that focus particles do not necessarily require a contrastive pitch accent.

An objection might be that the lack of acceptability differences indicates that participants did not perceive the difference between the accent conditions. Such an objection is ruled out by data from the truth value judgment task: participants computed more exhaustive inferences in the condition with $\mathrm{L}+\mathrm{H}^{*}$ compared to $\mathrm{H}^{*}$, indicating that the $\mathrm{L}+\mathrm{H}^{*}$ accent was perceived as more contrastive than the $\mathrm{H}^{*}$ accent (see also Fraundorf et al. 2010 for a similar finding). Interestingly, participants were equally able to derive such an inference in the $\mathrm{L}+\mathrm{H}^{*}$ condition and the explicit only conditions, at least in terms of the absence of a simple effect comparing the $\mathrm{L}+\mathrm{H}^{*}$ and only condition. In the condition with also, participants inferred the truth of the alternative proposition in both intonational conditions. 
In addition, the reaction time data showed that when listeners access the final interpretation from memory, the $\mathrm{L}+\mathrm{H}^{*}$ accent makes the exhaustive inference equally available as explicit only. Yet statistical analysis with contrast coding did not reveal interactions between accent type and the exhaustive conditions.

$L+H^{*}$ vs. $H^{*}$ : categorical or gradient? As noted in the introduction, it is an open question whether the distinction between the $\mathrm{H}^{*}$ and $\mathrm{L}+\mathrm{H}^{*}$ accent is categorical or gradient. The current experiment showed that the $\mathrm{L}+\mathrm{H}^{*}$ creates a strong bias towards an exhaustive interpretation. It seemed that participants encoded this interpretation because it was just as available as the exhaustive assertion of only. Yet two aspects speak against the assumption that the $\mathrm{L}+\mathrm{H}^{*}$ accent conventionally encodes exhaustivity. First, if the $\mathrm{L}+\mathrm{H}^{*}$ had a conventionalized contrastive meaning, it should not be compatible with the additive focus particle also, which expresses the truth of alternative propositions. However, participants' naturalness judgments for the condition with also $-\mathrm{L}+\mathrm{H}^{*}$ were not degraded relative to the other conditions and the accent type did not reduce participants' endorsements of the alternative statement. Second, if the distinction between $\mathrm{H}^{*}$ and $\mathrm{L}+\mathrm{H}^{*}$ were categorical, we would expect participants to be undecided between different readings in the $\mathrm{H}^{*}$ condition. Yet participants also derived quite a high number of implicatures in the condition with $\mathrm{H}^{*}$ (more than expected by chance, as shown by a one-sided t test: $\mathrm{t}=-3.39, p<0.01$ ).

The current data are in line with an eye-tracking study by Watson et al. (2008) which suggested that the $\mathrm{H}^{*}$ accent is compatible with both new and contrastive referents while $\mathrm{L}+\mathrm{H}^{*}$ creates a bias towards previously-mentioned contrastive referents. Moreover, two recent phonetic investigations of the $\mathrm{H}^{*}$ and $\mathrm{L}+\mathrm{H}^{*}$ accent in German conclude that the distinction between $\mathrm{H}^{*}$ and $\mathrm{L}+\mathrm{H}^{*}$ is gradient. Kügler and Gollrad (2015) showed that participants reliably distinguished contrastive and non-contrastive interpretations; however, interpretations were driven by phonetic characteristics (pitch height and alignment differences) and not by the leading low tone of the $\mathrm{L}+\mathrm{H}^{*}$ or the absence thereof. A corpus study by Grice et al. (2017) found that $\mathrm{L}+\mathrm{H}^{*}$ accents occurred mostly in contexts with contrastive focus, but also when the accented material denoted new information. $\mathrm{H}^{*}$ accents were used in both contexts to a similar degree. In conclusion, these recent studies and the current data are more compatible with a view in which the $\mathrm{L}+\mathrm{H}^{*}$ is a more contrastive variant of the $\mathrm{H}^{*}$ accent. Further, the $\mathrm{L}+\mathrm{H}^{*}$ accent does not seem to conventionally encode contrast; instead its interpretation interacts with the context in which it is used. If the $\mathrm{L}+\mathrm{H}^{*}$ accent did conventionally encode exhaustivity, we would expect to see the same processing signatures as for the exhaustive assertion of only. This claim will be further tested in Experiment 2, where alternative statements are presented directly after exposure to the stimuli.

Information structure and inference computation In the current experiment, the focused noun was always given in the preceding context sentence and the rest of the critical sentence provided new information, hence the implicature trigger appeared in topic position. ${ }^{4}$ Rooth (1992) observed that depending on which part of an utterance is focused, different implicatures arise, since focus determines the set of relevant

\footnotetext{
4 The focus associate was presented in subject position so that the pragmatic function of pitch accents concerning exhaustivity could be disentangled from effects related to focus association. It should be noted that results might change if focus association patterns were ambiguous.
} 
alternatives (see examples (1a) and (1b)). Several other theories have posited the even stronger view that implicatures can only occur in certain information-structural positions. van Kuppevelt (1996) argues that implicatures arise in comment/focus position, where they are entailments of the utterance (see also Fretheim 1992). If the scalar item occurs in topic position, on the other hand, no implicature is triggered unless a novel question under discussion can be accommodated. In contrast, Lee (2008) mainly discusses implicatures in contrastive topic position and concludes that certain intonational contours trigger a conventional implicature.

The current data show that the $\mathrm{L}+\mathrm{H}^{*}$ accent makes the implicature highly prevalent in contrastive topic position. However, note that around $70 \%$ of the participants also derived an implicature with the more neutral $\mathrm{H}^{*}$ accent. These findings are inconsistent with the view of van Kuppevelt (1996), according to whom implicatures should never occur in topic position. Experimental evidence against this claim was also found by Zondervan (2010) and Degen (2015). For example, Degen (2015) presents corpus data showing that implicatures occur more frequently in subject position compared to object position.

Presupposition accommodation The current experiment used the additive particle also as a control condition and revealed two findings concerning presupposition accommodation. First, the data show that listeners inferred the presupposition of also even when it was not contextually introduced. Second, the accent type manipulation did not affect participants' judgments. In many accounts, also is considered a hard presupposition trigger, meaning that (i) the presupposition of also is always triggered and (ii) that it cannot be accommodated easily (e.g., Abusch 2002; Kripke 2009). The items did not introduce the presupposition of also. Nevertheless, participants were willing to accommodate this presupposition. This is evident in the high proportion of TRUE responses in the condition with also, as well as the naturalness ratings, which were as high as for the baseline condition with the $\mathrm{H}^{*}$ accent. This finding indicates that, at least in certain contexts, presupposition accommodation of hard triggers might be easier than previously thought, or at least not impossible (see also Singh et al. 2015 for further evidence that participants accommodate the presupposition of also). Schwarz (2015) found that the presupposition of also was integrated earlier than the exhaustive assertion of only, and Domaneschi et al. (2014) found that focus operators triggered a processing cost when their presupposition was not given in the context. In the current study, where the presupposition of also had to be accommodated, it was equally available as the exhaustive assertion of only.

\subsection{Experiment 2}

In Experiment 2, I investigate the processing paths underlying the different inferences by presenting the truth value judgment task directly after exposure to the discourses. Experiment 2 uses the same conditions and critical items as Experiment 1. Experiment 1 showed that the $\mathrm{L}+\mathrm{H}^{*}$ accent makes an exhaustive inference equally available in memory as overt only. If the $\mathrm{L}+\mathrm{H}^{*}$ accent conventionally encodes exhaustivity/contrast, we would expect to see the same processing signatures in the $\mathrm{L}+\mathrm{H}^{*}$ and only conditions. If, on the other hand, $\mathrm{L}+\mathrm{H}^{*}$ encourages the derivation of a pragmatic 
inference, we expect to see additional processing costs associated with the derivation of the inference in the $\mathrm{L}+\mathrm{H}^{*}$ condition compared to only.

In this experiment, I included a certainty rating after the truth value judgment as a second task. The certainty rating accessed whether focus intonation has an effect on the competence assumption (IV) and whether potential increased processing times might be due to a decision uncertainty - that is, a competition between different readings. If participants still perceive an ambiguity between the implicature reading and the literal reading in the $\mathrm{L}+\mathrm{H}^{*}$ case, certainty ratings should be lower than in the overt only condition.

\subsubsection{Methods}

Participants A total of 24 native speakers of German (21 female and 3 male, mean age 25.9 years, age range 20-29) were recruited from a participant pool at the Institute of Psychology of Humboldt University. Participants were paid seven Euros in compensation. None of them reported any vision or hearing difficulties.

Materials In Experiment 2, the same critical items as in Experiment 1 were used. The incoherent filler items were replaced with acceptable ones since no naturalness rating was required in this experiment. In total, participants saw 120 items $(60$ critical items and 60 fillers).

Procedure An on-screen instruction explained the structure of the experiment. Participants were told that they would have to answer questions about the content of a number of stories. As in Experiment 1, we told participants that the statements could be implicit in the story. Subsequently, participants were asked to rate how certain they were in giving their response on a scale from 1 (not at all certain) to 7 (very certain). Five practice trials were administered before the experiment started.

The experiment consisted of two paired tasks per item: a truth value judgment and a certainty rating. Figure 7 represents the structure of one experimental trial. The truth value judgment and certainty rating were administered in immediate succession.

Each experimental trial began with a central fixation cross displayed on the screen for $500 \mathrm{~ms}$. Then, participants heard an item over headphones and performed the truth value judgment. The statement was presented directly on the screen after participants had been exposed to the auditory item. A time window of up to 10,000 ms was allowed for the judgment. The statement was colored green so that participants could easily identify the judgment phase. After participants had responded, a fixation cross was displayed for $500 \mathrm{~ms}$. Then, participants performed the certainty rating using an array of numbers. A time window of up to $7000 \mathrm{~ms}$ was allowed for the certainty rating. After 20 experimental trials, participants were given a short break. In total, the experiment contained six experimental blocks and lasted about 45 minutes. 


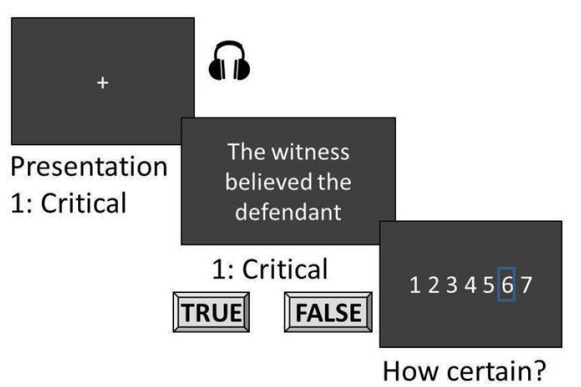

\section{Presentation + \\ Truth value \\ judgment + \\ Certainty rating}

Fig. 7 Trial sequence of one experimental trial (Exp. 2)

\subsubsection{Results}

Truth value judgment Fig. 8 shows the mean percentage of TRUE responses in the truth value judgment task.

The first mixed model analysis involved contrast coding of all factors. The results showed that there was no main effect of accent type. There was a significant difference between exhaustive and bare focus conditions $(\beta=-1.66, \mathrm{SE}=0.4, \mathrm{z}=-4.1$, $p<0.0001)$ as well as additive cases $(\beta=6.4, \mathrm{SE}=0.39, \mathrm{z}=16.25, p<0.0001)$. Finally, there was a significant interaction between accent type and additive conditions $(\beta=2.3, \mathrm{SE}=0.7, \mathrm{z}=3.3, p<0.001)$. This interaction reflects that $\mathrm{L}+\mathrm{H}^{*}$ had

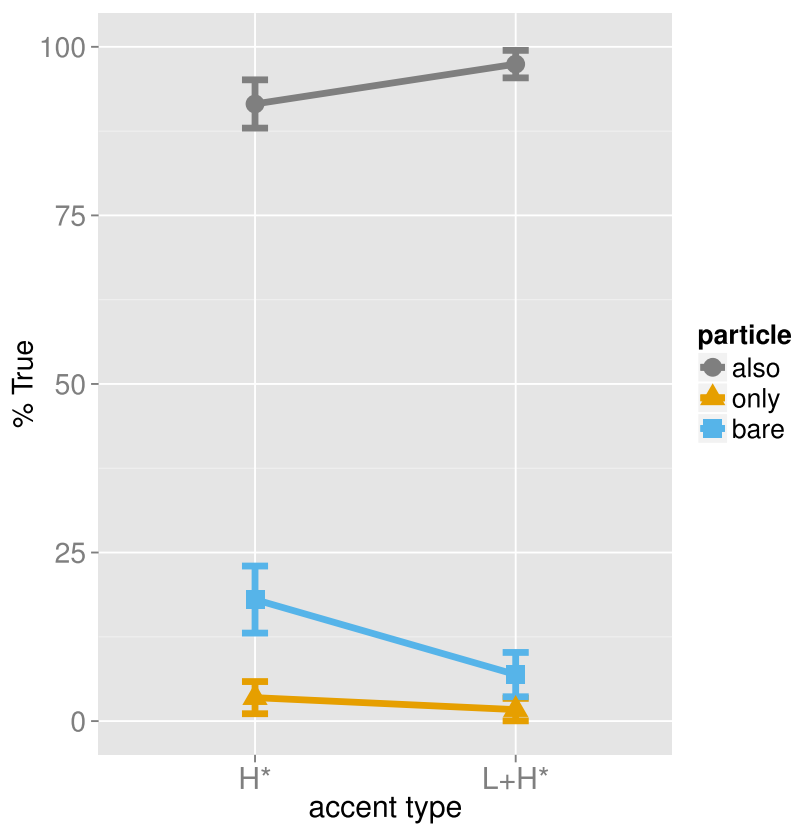

Fig. 8 Mean percentage of TRUE answers across conditions in Experiment 2 (circle $=$ also, square $=$ bare, triangle = only). Error bars represent $95 \%$ confidence intervals 
Table 8 Mixed effects model for truth judgment task in Experiment 2 (contrast coding)

\begin{tabular}{lrlcl}
\hline & $\beta$ & SE & z-value & $p$ value \\
\hline (Intercept) & -0.9988 & 0.1932 & -5.17 & \\
Accent & -0.1867 & 0.3275 & -0.57 & 0.568712 \\
Exhaustive & -1.6609 & 0.4052 & -4.099 & 0.001 \\
Additive & 6.4209 & 0.3951 & 16.252 & 0.001 \\
Accent:exhaustive & 0.3961 & 0.8099 & 0.489 & 0.624782 \\
Accent:additive & 2.3045 & 0.6989 & 3.297 & 0.000976 \\
\hline
\end{tabular}

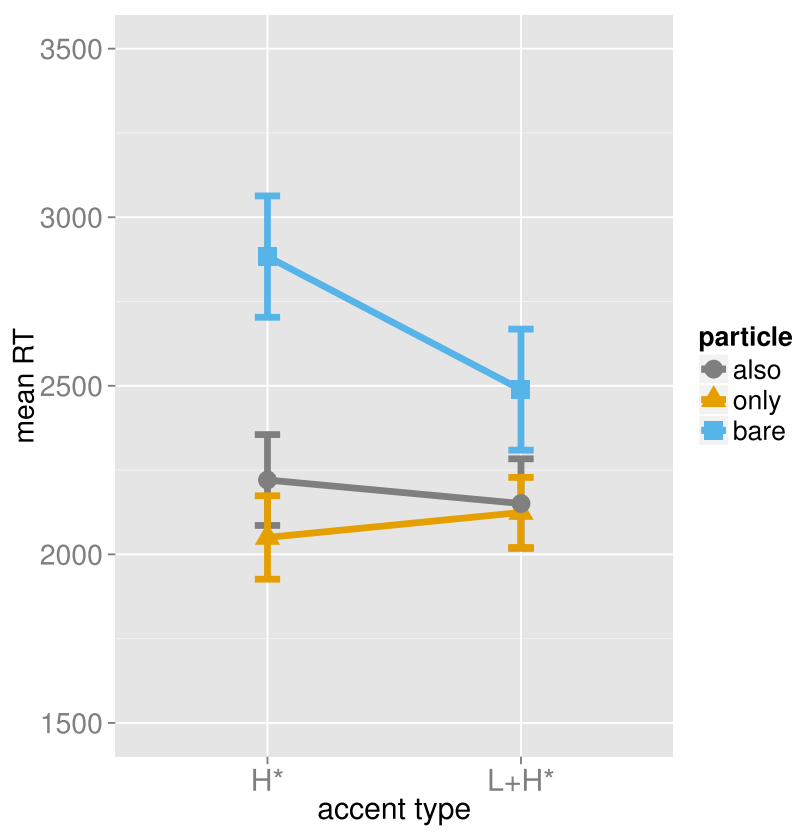

Fig. 9 Mean RT for expected response in truth value judgment task in Experiment 2 (circle $=$ also, answer TRUE; square = bare, answer FALSE; triangle = only, answer FALSE). Error bars represent $95 \%$ confidence intervals

a different effect in the additive focus particle condition compared to the exhaustive conditions. The results of the mixed model are detailed in Table 8.

Again a post hoc model with the bare $\mathrm{L}+\mathrm{H}^{*}$ condition as reference was computed. This model showed a difference between the $\mathrm{L}+\mathrm{H}^{*}$ and $\mathrm{H}^{*}$ conditions $(\beta=1.28$, $\mathrm{SE}=0.49, \mathrm{z}=2.59, p<0.001)$, as well as a difference between $\mathrm{L}+\mathrm{H}^{*}$ and only $(\beta=-1.48, \mathrm{SE}=0.69, \mathrm{z}=-2.11, p<0.05)$. Further, there was a difference between the bare $\mathrm{L}+\mathrm{H}^{*}$ and also conditions $(\beta=7.0, \mathrm{SE}=0.74, \mathrm{z}=9.5, p<$ $0.0001)$ as well as an interaction between accent and also conditions $(\beta=-2.7$, $\mathrm{SE}=0.82, \mathrm{z}=-3.1, p<0.001)$. This interaction reflects that participants gave more TRUE responses in the also- $\mathrm{L}+\mathrm{H}^{*}$ condition compared to the also- $\mathrm{H}^{*}$ condition. The model is shown in Table 15 of 'Appendix A'. 
Table 9 Mixed effects model for RTs of expected responses in Experiment 2 (contrast coding)

\begin{tabular}{lclll}
\hline & Estimate & $\mathrm{SE}$ & $\mathrm{t}$-value & $p$ value \\
\hline (Intercept) & 7.65597 & 0.04504 & 169.993 & \\
Accent & -0.05052 & 0.02841 & -1.778 & 0.086153 \\
Exhaustive & -0.2179 & 0.03001 & -7.26 & 0.0001 \\
Additive & -0.07188 & 0.02606 & -2.759 & 0.007873 \\
Accent:exhaustive & 0.21599 & 0.06 & 3.6 & 0.000675 \\
Accent:additive & 0.02071 & 0.0521 & 0.397 & 0.692629 \\
\hline
\end{tabular}

The reaction times for TRUE answers in the also conditions and FALSE answers in the $\mathrm{H}^{*}, \mathrm{~L}+\mathrm{H}^{*}$, and only-conditions are displayed in Fig. 9. The log-RTs were first analysed with contrast coding of all factors. The linear mixed model showed that there was a marginal effect of accent type $(\beta=-0.05, \mathrm{SE}=0.028, \mathrm{t}=-1.78$, $p=0.08)$. There were main effects comparing bare and exhaustive conditions ( $\beta=$ $-0.02, \mathrm{SE}=0.03, \mathrm{t}=-7.26, p<0.0001)$ as well as exhaustive and additive ones $(\beta=-0.07, \mathrm{SE}=0.03, \mathrm{t}=-2.76, p<0.0001)$, indicating that participants were responding faster to items with lexical particles. Crucially, there was an interaction between accent type and the exhaustive condition $(\beta=0.21, \mathrm{SE}=0.06, \mathrm{t}=3.6$, $p<0.001$ ), showing that responses were faster in the bare $\mathrm{L}+\mathrm{H}^{*}$ compared to $\mathrm{H}^{*}$ condition, while this difference was absent in the conditions with only. No interaction of accent type with the additive conditions was found $(p=0.69)$. The results of the mixed model are detailed in Table 9.

The second model with treatment coding revealed that reaction times in the bare $\mathrm{L}+\mathrm{H}^{*}$ condition were significantly faster than in the $\mathrm{H}^{*}$ condition $(\beta=0.16, \mathrm{SE}=$ $0.04, \mathrm{t}=3.78, p<0.0001)$. In turn, reaction times were faster in the condition with only $(\beta=-0.1, \mathrm{SE}=0.05, \mathrm{t}=-2.3, p<0.05)$ and with also relative to the $\mathrm{L}+\mathrm{H}^{*}$ condition $(\beta=-0.11, \mathrm{SE}=0.05, \mathrm{t}=-2.4, p<0.05)$. Further, there were interactions with the accent type in both particle conditions $\left(\mathrm{H}^{*}:\right.$ also: $\beta=-0.13$, $\mathrm{SE}=0.06, \mathrm{t}=-2.13, p<0.05$, and $\mathrm{H}^{*}:$ only: $\beta=-0.21, \mathrm{SE}=0.06, \mathrm{t}=-3.6$, $p<0.001)$. This shows that in the individual comparisons the $\mathrm{L}+\mathrm{H}^{*}$ yielded slower responses than either kind of focus particle. The model is provided in Table 17 in 'Appendix B'.

Certainty rating Finally, I analysed the ratings from the certainty task. Table 10 presents the mean certainty ratings across conditions for all responses.

The responses were analysed with a linear mixed effects model involving contrast coding of the factors accent type, particle presence, particle type, and their interactions, as well as random effects and random slopes. The results show that participants indi-

Table 10 Mean certainty ratings across conditions

\begin{tabular}{llll}
\hline Accent/Particle & Only & Also & Bare \\
\hline $\mathrm{H}^{*}$ & 6.5 & 5.9 & 4.8 \\
$\mathrm{~L}+\mathrm{H}^{*}$ & 6.6 & 6.1 & 5.3 \\
\hline
\end{tabular}


Table 11 Mixed effects model for certainty rating in Experiment 2 (contrast coding)

\begin{tabular}{lclrl}
\hline & \multicolumn{1}{l}{$\beta$} & $\mathrm{SE}$ & $\mathrm{t}$-value & $p$ value \\
\hline (Intercept) & 5.8507 & 0.1216 & 48.122 & \\
Accent & 0.251 & 0.1034 & 2.428 & 0.0201 \\
Exhaustive & 1.4796 & 0.1205 & 12.279 & 0.001 \\
Additive & 0.2261 & 0.1052 & 2.149 & 0.0361 \\
Accent:exhaustive & -0.4714 & 0.241 & -1.956 & 0.0556 \\
Accent:additive & -0.2124 & 0.2104 & -1.009 & 0.3174 \\
\hline
\end{tabular}

cated higher certainty in the $\mathrm{L}+\mathrm{H}^{*}$ compared to the $\mathrm{H}^{*}$ condition $(\beta=0.25, \mathrm{SE}=0.1$, $\mathrm{t}=2.4, p<0.05)$. There was also a significant difference between utterances with exhaustive only relative to the bare condition $(\beta=1.47, \mathrm{SE}=0.12, \mathrm{t}=12.28$, $p<0.001)$, and participants were more certain in the additive condition $(\beta=0.23$, $\mathrm{SE}=0.1, \mathrm{t}=2.15, p<0.05)$. Finally, there was a marginal interaction for the factor accent in the exhaustive conditions $(\beta=-0.47, \mathrm{SE}=0.24, \mathrm{z}=-1.96, p=0.056)$. The results of the mixed model are detailed in Table 11.

In addition, Table 18 in 'Appendix B' provides an analysis of the certainty data with treatment coding. The model again shows that certainty judgments were lower in the $\mathrm{H}^{*}$ compared to $\mathrm{L}+\mathrm{H}^{*}$ condition $(\beta=-0.55, \mathrm{SE}=0.17, \mathrm{t}=-3.2, p<0.01)$. There was also a significant difference in the individual comparison between $\mathrm{L}+\mathrm{H}^{*}$ and only $(\beta=1.24, \mathrm{SE}=0.17, \mathrm{t}=7.3, p<0.001)$ as well as also $(\beta=0.0 .74$, $\mathrm{SE}=0.17, \mathrm{t}=4.35, p<0.0001)$. Finally, there were marginal interactions between accent type and only $(\beta=0.47, \mathrm{SE}=0.24, \mathrm{t}=-1.96, p=0.056)$ and also conditions $(\beta=0.44, \mathrm{SE}=0.24, \mathrm{t}=1.85, p=0.069)$. In summary, the certainty ratings indicate that accent type mainly affected judgments in the bare focus conditions and participants were more certain overall in the conditions with overt focus particles.

Omnibus analysis across experiments In order to compare the main results of the two experiments, an omnibus analysis was carried out with the combined data. For this analysis, an additional binary factor experiment was included in the model, as well as the factors accent, particle, and a three-way interaction between experiment, accent, and particle conditions. The model showed that there was a main effect of accent across experiments $(\beta=0.04, \mathrm{SE}=0.02, \mathrm{z}=2.1, p<0.05)$, in addition to main effects of exhaustive and additive particle conditions (exhaustive: $\beta=-0.1, \mathrm{SE}=0.025$, $\mathrm{z}=-4.6, p<0.0001$ and additive: $\beta=0.071, \mathrm{SE}=0.022, \mathrm{z}=32.6, p<0.0001)$. Crucially, there were also significant interactions between accent type and particle conditions (accent:exhaustive: $\beta=-0.1, \mathrm{SE}=0.05, \mathrm{z}=-2.0, p<0.05$ and accent:additive: $\beta=-0.1, \mathrm{SE}=0.04, \mathrm{z}=-2.5, p<0.05)$. In addition, there was an interaction between experiment and the additive condition $(\beta=0.35, \mathrm{SE}=0.03$, $\mathrm{z}=10.69, p<0.0001)$. These results show that, overall, pitch accents had a different effect in bare and particle conditions: while the $\mathrm{L}+\mathrm{H}^{*}$ accent facilitated the derivation of an exhaustivity implicature in the bare conditions, it did not increase the proportion of exhaustive responses in the conditions with overt only. In the case of also, the $\mathrm{L}+\mathrm{H}^{*}$ increased the number of TRUE responses, especially in Experiment 2, which involved the immediate delay. Table 12 details the results of the model with contrast coding for the truth value judgment data. Table 19 in 'Appendix C' further provides a model with 
Table 12 Mixed effects model for truth value judgment data across Experiments 1 and 2 (contrast coding)

\begin{tabular}{lcccc}
\hline & \multicolumn{1}{c}{$\beta$} & SE & z-value & $p$ value \\
\hline (Intercept) & 0.3790436 & 0.0148814 & 25.471 & \\
Accent & 0.0422806 & 0.0201621 & 2.097 & 0.0406 \\
Exhaustive & -0.1132574 & 0.0247031 & -4.585 & 0.0001 \\
Additive & 0.7029485 & 0.0215933 & 32.554 & 0.0001 \\
Experiment & -0.0295217 & 0.0265822 & -1.111 & 0.2716 \\
Accent:exhaustive & -0.1004055 & 0.049405 & -2.032 & 0.047 \\
Accent:additive & -0.1075324 & 0.0431852 & -2.49 & 0.0159 \\
Accent:experiment & -0.0387584 & 0.0301531 & -1.285 & 0.2027 \\
Exhaustive:experiment & 0.0280931 & 0.0369554 & 0.76 & 0.4496 \\
Additive:experiment & 0.3538877 & 0.0322844 & 10.962 & 0.0001 \\
Accent:exhaustive:experiment & -0.0001461 & 0.0739077 & -0.002 & 0.9984 \\
Accent:additive:experiment & -0.0340807 & 0.0645648 & -0.528 & 0.5992 \\
\hline
\end{tabular}

Table 13 Mixed effects model for reaction time data across Experiments 1 and 2 (contrast coding)

\begin{tabular}{lcccc}
\hline & $\beta$ & $\mathrm{SE}$ & $\mathrm{t}$-value & $p$ value \\
\hline (Intercept) & 7.6575 & 0.04548 & 168.376 & \\
Accent & 0.05143 & 0.02939 & 1.75 & 0.083743 \\
Exhaustive & -0.2191 & 0.0361 & -6.07 & 0.0001 \\
Additive & -0.07096 & 0.03142 & -2.259 & 0.026498 \\
Experiment & 0.16636 & 0.0619 & 2.688 & 0.00991 \\
Accent:exhaustive & -0.21441 & 0.07217 & -2.971 & 0.00385 \\
Accent:additive & -0.02336 & 0.06282 & -0.372 & 0.710992 \\
Accent:experiment & -0.03583 & 0.0283 & -1.266 & 0.205575 \\
Exhaustive:experiment & 0.12896 & 0.03466 & 3.72 & 0.000204 \\
Additive:experiment & 0.05397 & 0.03045 & 1.772 & 0.076464 \\
Accent:exhaustive:experiment & 0.08114 & 0.06927 & 1.171 & 0.241572 \\
Accent:additive:experiment & -0.08497 & 0.06067 & -1.401 & 0.161478 \\
\hline
\end{tabular}

treatment coding, confirming the findings in terms of simple effects between pitch accent and particle conditions, as well as interactions between particle conditions and experiment.

Further, an omnibus model for the reaction data was fitted with the factors experiment, accent, and particle. The model showed that there was a marginal effect of accent across experiments $(\beta=0.05, \mathrm{SE}=0.03, \mathrm{t}=1.75, p=0.08)$, in addition to main effects of exhaustive and additive particle conditions (exhaustive: $\beta=-0.2$, $\mathrm{SE}=0.04, \mathrm{t}=-6.1, p<0.0001$ and additive: $\beta=-0.071, \mathrm{SE}=0.03, \mathrm{t}=-2.26$, $p<0.05)$. There was again a significant interaction between accent type and exhaustive condition $(\beta=-0.2, \mathrm{SE}=0.07, \mathrm{t}=-2.97, p<0.01)$, but not the additive condition. In addition, there was an interaction between experiment and exhaustive condition $(\beta=0.13, \mathrm{SE}=0.03, \mathrm{t}=3.7, p<0.001)$ and a marginal interaction 
in the additive condition $(\beta=0.05, \mathrm{SE}=0.03, \mathrm{t}=1.7, p=0.076)$. The results of the model are summarized in Table 13, as well as Table 20 in Appendix C, which provides a model with treatment coding. This model shows that while there was a simple effect comparing the $\mathrm{H}^{*}$ and $\mathrm{L}+\mathrm{H}^{*}$ conditions $(\beta=0.14, \mathrm{SE}=0.04, \mathrm{t}=3.1$, $p<0.01$ ), no simple effects were present in the comparison between $\mathrm{L}+\mathrm{H}^{*}$ and either type of particle (only: $p=0.13$, also: $p=0.32$ ). Instead, there were interactions between accent type and particle conditions ( $\mathrm{H}^{*}:$ only: $\beta=-0.17, \mathrm{SE}=0.06$, $\mathrm{t}=-2.7, p<0.01 ; \mathrm{H}^{*}:$ also: $\left.\beta=-0.15, \mathrm{SE}=0.06, \mathrm{t}=-2.35, p<0.05\right)$, as well as interactions across experiments and particle conditions (only:experiment: $\beta=-0.09, \mathrm{SE}=0.05, \mathrm{t}=-1.9, p=0.06$; also:experiment: $\beta=-0.13$, $\mathrm{SE}=0.05, \mathrm{t}=-2.86, p<0.01)$. Overall, the reaction time data indicate that $\mathrm{L}+\mathrm{H}^{*}$ accents facilitated processing relative to $\mathrm{H}^{*}$ accents for bare focus but not particle conditions. Further, response delays in pitch accent conditions relative to overt particle conditions were mainly present in Experiment 2, involving the immediate delay.

\subsection{Discussion}

Summary of findings Experiment 2 provides three main insights. First, the judgment data provide further evidence that the $\mathrm{L}+\mathrm{H}^{*}$ creates a strong bias for listeners to derive an implicature. Second, the analysis of the reaction time data showed that the processing of the accent conditions was delayed relative to the processing of the exhaustive assertion of only. Hence, the processing of an exhaustive implicature incurs a processing cost. Third, the certainty rating showed that the $\mathrm{H}^{*}$ condition received lowest ratings, the $\mathrm{L}+\mathrm{H}^{*}$ accent increased certainty levels, but not to the same degree as focus particles. This suggests that participants were still aware of the fact that the utterances with bare focus had two different interpretations-one reading with the implicature and one without.

Experiment 2 revealed two additional findings concerning the comparison of additive and exclusive focus particles. First, listeners were more likely to accommodate the presupposition of also with the $\mathrm{L}+\mathrm{H}^{*}$ accent compared to the $\mathrm{H}^{*}$ accent, while accent type had no effect in the only conditions. Second, participants indicated a lower degree of certainty in presupposition accommodation with also compared to processing asserted content of only.

Furthermore, a cross-experiment analysis revealed that there were interactions across accent and particle conditions, as well as interactions between experiment version and particle conditions for judgment and reaction time data. These findings suggest that overall the $\mathrm{L}+\mathrm{H}^{*}$ mainly encourages inference processing in bare accent conditions, but not when preceded by a focus particle. Such facilitatory effects mainly show in Experiment 2 when the decision is made immediately, but tend to fade away when a response delay is introduced. Taken together the findings highlight the contextdependent role of focus prosody: in contexts with additive particles listeners are more likely to accommodate a presupposition about a salient contextual alternative, while listeners use focus prosody to derive an exhaustive implicature in the absence of lexical cues. When preceded by lexical only, intonation does not make any further contribution to deriving the exhaustive inference. 
Processing costs at different stages of implicature computation The comparison of different accounts of implicature computation (Sect. 2.2) suggested that it would be useful to separate different stages of inference computation. Previous experimental studies revealed that alternatives are recognized faster with the $\mathrm{L}+\mathrm{H}^{*}$ accent compared to only. In particular, Gotzner et al. (2013) used the same materials as the current study and showed that $\mathrm{L}+\mathrm{H}^{*}$ facilitated the recognition of the mentioned alternative relative to the $\mathrm{H}^{*}$ accent while only caused an interference effect. Hence, in alternative activation there is a processing advantage with $\mathrm{L}+\mathrm{H}^{*}$ accents compared to overt only. The current inferential study, on the other hand, revealed that the inference about the alternative is processed more slowly with the $\mathrm{L}+\mathrm{H}^{*}$ (and slowest with $\mathrm{H}^{*}$ ), even though the alternatives are made highly salient by the $\mathrm{L}+\mathrm{H}^{*}$ accent. This suggests that focus prosody facilitates implicature processing above and beyond its role in activating alternatives. At the same time, the activation and selection of alternatives cannot be the reason for the processing cost observed in the computation of implicatures in the current study. Since the $\mathrm{L}+\mathrm{H}^{*}$ condition may have had an advantage in alternative activation, we might expect that the inference is processed equally fast or even faster than the exhaustive assertion of only. However, the data show that the implicature is processed more slowly than the exhaustive assertion, so there must be another source of processing delay in the bare accent conditions.

Concerning the nature of the processing cost in implicature computation, previous studies discussed two further possibilities: either the processing cost is due to the ambiguity between two different parses (Marty 2013) or it is associated with the inferential process itself (e.g., epistemic strengthening). Specifically, one account of the processing cost could be that there is a competition between different readings, particularly during immediate processing stages. So, focus intonation might lead to a bias for an exhaustive interpretation, but might not eliminate competition between the implicature and the literal reading.

The certainty ratings indicated that participants were aware of the fact that the sentences without lexical particles had a second literal reading. That is, the certainty ratings were lowest in the condition with $\mathrm{H}^{*}$, intermediate in the $\mathrm{L}+\mathrm{H}^{*}$ condition, and highest in the condition with only. Uncertainty may, in turn, have led participants to slow down their decision to reject the alternative statement. Recall that in Experiment 1 no difference between the $\mathrm{L}+\mathrm{H}^{*}$ and only conditions was found, neither in the likelihood that the inference was derived nor in its speed. In this experiment, participants accessed their final interpretation of the utterances from memory; therefore ambiguity between different readings must have already been resolved. Hence, the competition between different readings is a potential source for the processing costs in implicature computation observed in Experiment 2.

An additional reason why focus particles may have encouraged faster processing of the associated inferences in Experiment 2 is that focus particles lexically express the relation between the focused element and its alternatives. In Rooth (1992) the ordinary semantic value has direct access to the focus semantic value, which provides the locus for focus particles. For this reason, salient alternatives can be used immediately by the focus operator. In the bare $\mathrm{L}+\mathrm{H}^{*}$ condition, on the other hand, there is a less direct relationship between the set of alternatives and compositional semantic interpretation. 
Specifically, the interpretation of sentences with bare focus is dependent on further pragmatic considerations.

One such factor may be the listener's assessment of the speaker's competence, especially when considering the epistemic step postulated in Neo-Gricean accounts of implicature. As shown in the study by Bergen and Grodner (2012), considerations of epistemic certainty lead to a penalty in processing implicatures, but not the exhaustive assertion of only. Hence, a potential factor leading to slower processing times in the bare focus conditions is the lower degree of epistemic strength, as indicated in the certainty ratings of Experiment 2. Speakers may use pitch accents to indicate their degree of certainty, and listeners may take pitch accents as a cue that an inference should be derived. Pitch accents may thus help listeners evaluate the speaker's knowledge state or their opionatedness about relevant alternatives.

Breheny et al. (2013) argued that a simple focus-related account is unable to incorporate the sensitivity of implicature to the presumed epistemic state of the speaker. That is, if all that mattered for implicature derivation were salient alternatives, no knowledge effects in implicature computation should be observed. The authors concluded that focus may only be an indirect or conditional cue to implicature derivation. The current data show that focus intonation makes exhaustivity implicatures highly prevalent even when relevant alternatives are salient in the linguistic context. This extends previous findings by Gotzner et al. (2013) and Tomlinson et al. (2017), showing that focal pitch accents facilitate the inferential process itself, in addition to activating contextual alternatives. In keeping with Breheny et al., I assume that there are additional conditions determining whether an implicature is derived, such as contextual factors related to epistemic information.

\section{Conclusions: the dual function of focal pitch accents}

In the Introduction, three possibilities were discussed as to how focus intonation might affect implicature computation. The current study and previous findings suggest that focus intonation affects both the derivation of alternatives and the implicature computation mechanism itself. Further, the data provide evidence for a view in which the distinction between $\mathrm{H}^{*}$ and $\mathrm{L}+\mathrm{H}^{*}$ pitch accents is gradient, in that both accents are compatible with an exhaustive interpretation.

First, the study showed that $\mathrm{L}+\mathrm{H}^{*}$ makes an exhaustive interpretation highly prevalent, but this was also the most frequent interpretation in the $\mathrm{H}^{*}$ condition. Second, listeners required additional processing resources to derive the implicature, compared to the exhaustive assertion of only, and indicated lower certainty in deriving the implicature. Third, the particle also was perceived as equally natural with $\mathrm{H}^{*}$ and $\mathrm{L}+\mathrm{H}^{*}$ accent; and with the latter, participants inferred the truth of the alternative statement to a higher extent (Experiment 2). In sum, these results indicate that $\mathrm{L}+\mathrm{H}^{*}$ does not conventionally encode contrast. Instead, its function varies depending on the context in which it is used. What is common among the different uses is that $\mathrm{L}+\mathrm{H}^{*}$ increases the salience of alternatives (as shown in independent studies by Braun and Tagliapietra 2010; Gotzner et al. 2013; Husband and Ferreira 2016). As a consequence, relevant alternatives can be fed more readily into the implicature computation mechanism and the inference is 
derived more quickly than with the $\mathrm{H}^{*}$ accent. In the current study, the $\mathrm{L}+\mathrm{H}^{*}$ accent had a facilitatory effect on implicature computation even when alternatives were salient in the linguistic context. This suggests that focus intonation affects the implicature computation mechanism above and beyond its role in generating alternatives.

In conclusion, the results suggest a dual function of focal pitch accents in (i) helping listeners to identify relevant alternatives in context and (ii) providing a strong cue that an inference should be derived. This role of prosody is context dependent and interacts with lexical cues preceding the relevant pitch accents.

Acknowledgements Experiment 1 of this paper appeared in the Proceedings of the Formal and Experimental Pragmatics Workshop at ESSLLI (Gotzner and Spalek 2014). For helpful comments, I am grateful to the audiences of this workshop, as well as to Cory Bill, Stephen Crain, Filippo Domaneschi, Jesse Harris, Brian Leahy, Jacopo Romoli, Uli Sauerland, Katharina Spalek, Stephanie Solt, Jack Tomlinson, Judith Tonhauser, Katsuhiko Yabushita, and Peng Zhou. I am particularly grateful to the anonymous reviewers, whose feedback has substantially improved previous manuscript versions. I would also like to thank Felicitas Enders for help with data collection. This work was supported by the DFG as part of the collaborative research centre SFB 632 Information Structure. Nicole Gotzner is currently supported by a DFG Grant within the priority program SPP 1727 Xprag.de (Grant No. BE 4348/4-1). This grant provided funding for open access.

Open Access This article is distributed under the terms of the Creative Commons Attribution 4.0 International License (http://creativecommons.org/licenses/by/4.0/), which permits unrestricted use, distribution, and reproduction in any medium, provided you give appropriate credit to the original author(s) and the source, provide a link to the Creative Commons license, and indicate if changes were made.

\section{Appendix}

\section{Appendix A: Post hoc analyses for Experiment 1}

See Tables 14 and 15.

Table 14 Mixed effects model for truth value judgment task in Experiment 1 (treatment coding, reference: bare $\mathrm{L}+\mathrm{H}^{*}$ )

Table 15 Mixed effects model for RTs of expected responses in Experiment 1 (treatment coding, reference: bare $\left.\mathrm{L}+\mathrm{H}^{*}\right)$

\begin{tabular}{lrlcl}
\hline & \multicolumn{1}{l}{$\beta$} & $\mathrm{SE}$ & $\mathrm{z}$-value & $p$ value \\
\hline (Intercept) & -1.4945 & 0.2936 & -5.091 & 0.0001 \\
Bare H* & 0.8551 & 0.3166 & 2.701 & 0.00692 \\
Also & 2.7188 & 0.3739 & 7.27 & 0.0001 \\
Only & -0.5899 & 0.3855 & -1.53 & 0.12596 \\
Bare $\mathrm{H}^{*}$ :also & -0.8986 & 0.4502 & -1.996 & 0.04594 \\
Bare $\mathrm{H}^{*}$ :only & -0.4441 & 0.4683 & -0.948 & 0.343 \\
\hline
\end{tabular}

\begin{tabular}{lclrr}
\hline & \multicolumn{1}{l}{$\beta$} & \multicolumn{1}{l}{$\mathrm{SE}$} & \multicolumn{1}{c}{ z-value } & $p$ value \\
\hline (Intercept) & 7.8185 & 0.06113 & 127.893 & 0.0001 \\
Bare $\mathrm{H}^{*}$ & 0.12094 & 0.0641 & 1.887 & 0.0644 \\
Also & 0.02354 & 0.06333 & 0.372 & 0.7115 \\
Only & -0.02292 & 0.06258 & -0.366 & 0.7156 \\
Bare $\mathrm{H}^{*}$ :also & -0.17776 & 0.09016 & -1.972 & 0.0537 \\
Bare $\mathrm{H}^{*}$ :only & -0.13687 & 0.08938 & -1.531 & 0.1316 \\
\hline
\end{tabular}




\section{Appendix B: Post hoc analyses for Experiment 2}

See Tables 16, 17, and 18.

Table 16 Mixed effects model for judgment task in Experiment 2 (treatment coding, reference: bare $\left.\mathrm{L}+\mathrm{H}^{*}\right)$
Table 17 Mixed effects model for RTs of expected responses in Experiment 2 (treatment coding, reference: bare $\left.\mathrm{L}+\mathrm{H}^{*}\right)$

Table 18 Mixed effects model for certainty ratings in Experiment 2 (treatment coding, reference: bare $\left.\mathrm{L}+\mathrm{H}^{*}\right)$

\begin{tabular}{lrrrl}
\hline & \multicolumn{1}{c}{$\beta$} & $\mathrm{SE}$ & $\mathrm{z}$-value & $p$ value \\
\hline (Intercept) & -2.9724 & 0.4385 & -6.778 & 0.0001 \\
Bare $\mathrm{H}^{*}$ & 1.2811 & 0.4948 & 2.589 & 0.009626 \\
Also & 6.9859 & 0.7378 & 9.469 & 0.0001 \\
Only & -1.4771 & 0.6996 & -2.111 & 0.034732 \\
Bare $\mathrm{H}^{*}$ :also & -2.7386 & 0.8262 & -3.315 & 0.000917 \\
Bare $\mathrm{H}^{*}$ :only & -0.3716 & 0.8454 & -0.44 & 0.660266 \\
\hline
\end{tabular}

\begin{tabular}{lclrl}
\hline & Estimate & SE & t-value & $p$ value \\
\hline (Intercept) & 7.70607 & 0.05515 & 139.733 & 0.0001 \\
Bare H* & 0.16225 & 0.04286 & 3.785 & 0.000383 \\
Also & -0.1148 & 0.04767 & -2.408 & 0.022867 \\
Only & -0.10997 & 0.04746 & -2.317 & 0.028176 \\
Bare $\mathrm{H}^{*}$ :also & -0.12721 & 0.05977 & -2.128 & 0.038049 \\
Bare $\mathrm{H}^{*}$ :only & -0.21254 & 0.05951 & -3.571 & 0.000781 \\
\hline
\end{tabular}

\begin{tabular}{lrlrl}
\hline & Estimate & $\mathrm{SE}$ & $\mathrm{t}$-value & $p$ value \\
\hline (Intercept) & 5.3147 & 0.1697 & 31.313 & \\
Bare H* & -0.5567 & 0.1734 & -3.211 & 0.00224 \\
Also & 0.7407 & 0.1703 & 4.349 & 0.0001 \\
Only & 1.2439 & 0.1703 & 7.306 & 0.0001 \\
Bare $\mathrm{H}^{*}$ :also & 0.4459 & 0.2407 & 1.853 & 0.06936 \\
Bare $\mathrm{H}^{*}$ :only & 0.4714 & 0.241 & 1.956 & 0.05559 \\
\hline
\end{tabular}

\section{Appendix C: Post hoc analyses across Experiments 1 and 2}

See Tables 19 and 20. 
Table 19 Mixed effects model for truth value judgment data across Experiments 1 and 2 (treatment coding)

\begin{tabular}{lclrl}
\hline & $\beta$ & $\mathrm{SE}$ & $\mathrm{z}$-value & $p$ value \\
\hline (Intercept) & 0.14002 & 0.02729 & 5.131 & \\
$\mathrm{H}^{*}$ & 0.12755 & 0.03535 & 3.608 & 0.000674 \\
Also & 0.71743 & 0.03534 & 20.303 & 0.0001 \\
Only & -0.06339 & 0.03533 & -1.794 & 0.078387 \\
Experiment & -0.14568 & 0.03737 & -3.898 & 0.000128 \\
$\mathrm{H}^{*}$ :also & -0.1563 & 0.04996 & -3.129 & 0.002833 \\
$\mathrm{H}^{*}$ :only & -0.10018 & 0.04999 & -2.004 & 0.05 \\
$\mathrm{H}^{*}$ :experiment & -0.02881 & 0.04282 & -0.673 & 0.501081 \\
Also:experiment & 0.38058 & 0.04278 & 8.897 & 0.0001 \\
Only:experiment & 0.02703 & 0.04275 & 0.632 & 0.527284 \\
$\mathrm{H}^{*}$ :also:experiment & -0.03284 & 0.06045 & -0.543 & 0.586997 \\
$\mathrm{H}^{*}$ :only:experiment & 0.00153 & 0.06053 & 0.025 & 0.979841 \\
\hline
\end{tabular}

Table 20 Mixed effects model for reaction time data across Experiments 1 and 2 (treatment coding)

\begin{tabular}{lclrr}
\hline & $\beta$ & $\mathrm{SE}$ & $\mathrm{t}$-value & $p$ value \\
\hline (Intercept) & 7.76142 & 0.04408 & 176.084 & \\
$\mathrm{H}^{*}$ & 0.14216 & 0.04604 & 3.087 & 0.00312 \\
Also & -0.04479 & 0.04548 & -0.985 & 0.32908 \\
Only & -0.06769 & 0.04515 & -1.499 & 0.13979 \\
Experiment & -0.10826 & 0.06944 & -1.559 & 0.12323 \\
$\mathrm{H}^{*}$ :also & -0.1521 & 0.06472 & -2.35 & 0.02235 \\
$\mathrm{H}^{*}$ :only & -0.17384 & 0.06437 & -2.701 & 0.00921 \\
$\mathrm{H}^{*}$ :experiment & 0.04836 & 0.0507 & 0.954 & 0.34023 \\
Also:experiment & -0.13969 & 0.04884 & -2.86 & 0.00427 \\
Only:experiment & -0.08839 & 0.0477 & -1.853 & 0.06402 \\
$\mathrm{H}^{*}$ :also:experiment & 0.04355 & 0.07054 & 0.617 & 0.53707 \\
$\mathrm{H}^{*}$ :only:experiment & -0.08114 & 0.06927 & -1.171 & 0.24157 \\
\hline
\end{tabular}

\section{References}

Abusch, D. 2002. Lexical alternatives as a source of pragmatic presuppositions. In Proceedings of SALT 12, ed. B. Jackson, 1-19. Ithaca, NY: CLC Publications.

Alter, K., I. Mleinek, T. Rohe, A. Steube, and C. Umbach. 2001. Kontrastprosodie in Sprachproduktion und -perzeption. Linguistische Arbeitsberichte 77: 59-79.

Barr, D.J., R. Levy, C. Scheepers, and H.J. Tily. 2013. Random effects structure for confirmatory hypothesis testing: Keep it maximal. Journal of Memory and Language 68 (3): 255-278.

Bartels, C., and J. Kingston. 1994. Salient pitch cues in the perception of contrastive focus. The Journal of the Acoustical Society of America 95 (5): 2973-2973.

Bates, D., and D. Sarkar. 2007. Lme4: Linear mixed-effects models using s4 classes. 
Baumann, S., M. Grice, and S. Steindamm. 2006. Prosodic marking of focus domains-Categorical or gradient. In Proceedings of Speech Prosody 2006, ed. R. Hoffman and H. Mixdorff, 301-304. Dresden: TUD Press.

Bergen, L., and D.J. Grodner. 2012. Speaker knowledge influences the comprehension of pragmatic inferences. Journal of Experimental Psychology: Learning, Memory, and Cognition 38 (5): 1450.

Bott, L., and I. Noveck. 2004. Some utterances are underinformative: The onset and time course of scalar inferences. Journal of Memory and Language 51 (3): 437-457.

Bott, L., T. Bailey, and D. Grodner. 2012. Distinguishing speed from accuracy in scalar implicatures. Journal of Memory and Language 66 (1): 123-142.

Braun, B., and L. Tagliapietra. 2010. The role of contrastive intonation contours in the retrieval of contextual alternatives. Language and Cognitive Processes 25: 1024-1043.

Breheny, R., H.J. Ferguson, and N. Katsos. 2013. Taking the epistemic step: Toward a model of on-line access to conversational implicatures. Cognition 126 (3): 423-440.

Byram-Washburn, M. 2013. Narrowing the Focus: Experimental studies on exhaustivity and contrast. PhD thesis, University of Southern California.

Calhoun, S. 2009. What makes a word contrastive? Prosodic, semantic and pragmatic perspectives. In Where prosody meets pragmatics: Research at the interface (Studies in Pragmatics), vol. 8, ed. N.D.D. BarthWeingarten and A. Wichmann, 53-78. Bingley: Emerald Group Publishing.

Chemla, E., and L. Bott. 2014. Processing inferences at the semantics/pragmatics frontier: Disjunctions and free choice. Cognition 130 (3): 380-396.

Chemla, E., and R. Singh. 2014. Remarks on the experimental turn in the study of scalar implicature, part I. Language and Linguistics Compass 8 (9): 373-386.

Chevallier, C., I. Noveck, T. Nazir, L. Bott, V. Lanzetti, and D. Sperber. 2008. Making disjunctions exclusive. The Quarterly Journal of Experimental Psychology 61 (11): 1741-1760.

Chierchia, G. 2004. Scalar implicatures, polarity phenomena, and the syntax/pragmatics interface. Structures and Beyond 3: 39-103.

Chierchia, G. 2006. Broaden your views: Implicatures of domain widening and the logicality of language. Linguistic Inquiry 37 (4): 535-590.

Chierchia, G. 2013. Logic in grammar: Polarity, free choice, and intervention, vol. 2. Oxford: Oxford University Press.

De Neys, W., and W. Schaeken. 2007. When people are more logical under cognitive load: Dual task impact on scalar implicature. Experimental Psychology 54 (2): 128-133.

Degen, J. 2015. Investigating the distribution of some (but not all) implicatures using corpora and web-based methods. Semantics and Pragmatics 8 (11): 1-55.

Degen, J., and M. Tanenhaus. 2015. Processing scalar implicature: A constraint-based approach. Cognitive Science 39 (4): 667-710.

Degen, J., and M. Tanenhaus. 2016. Availability of alternatives and the processing of scalar implicatures: A visual world eye tracking study. Cognitive Science 40 (1): 172-201.

Dieussaert, K., S. Verkerk, E. Gillard, and W. Schaeken. 2011. Some effort for some: Further evidence that scalar implicatures are effortful. The Quarterly Journal of Experimental Psychology 64 (12): 2352-2367.

Domaneschi, F., E. Carrea, C. Penco, and A. Greco. 2014. The cognitive load of presupposition triggers: Mandatory and optional repairs in presupposition failure. Language, Cognition and Neuroscience 29 (1): 136-146.

Fox, D., and R. Katzir. 2011. On the characterization of alternatives. Natural Language Semantics 19 (1): 87-107.

Fraundorf, S., D. Watson, and A. Benjamin. 2010. Recognition memory reveals just how contrastive contrastive accenting really is. Journal of Memory and Language 63: 367-386.

Fretheim, T. 1992. The effect of intonation on a type of scalar implicature. Journal of Pragmatics 18 (1): $1-30$.

Gotzner, N. 2017. Alternative sets in language processing: How focus alternatives are represented in the mind. Palgrave Studies in Pragmatics, Language and Cognition. London: Palgrave Macmillan.

Gotzner, N., and K. Spalek. 2014. Exhaustive inferences and additive presuppositions: The interplay of focus operators and contrastive intonation. In Proceedings of the Formal and Experimental Pragmatics Workshop (ESSLII 2014), ed. J. Degen, M. Franke, and N. Goodman, 7-13. Tübingen University. 
Gotzner, N., and K. Spalek. 2016. The role of contrastive and non-contrastive associates in the interpretation of focus particles. Discourse Processes 54 (8): 638-654. https://doi.org/10.1080/0163853X.2016. 1148981.

Gotzner, N., and K. Spalek. 2017. The connection between focus and implicatures: Investigating alternative activation under working memory load. In Linguistic and Psycholinguistic Approaches on Implicatures and Presuppositions, ed. S. Pistoia-Reda, and F. Domaneschi, 175-198. London: Palgrave Macmillan.

Gotzner, N., K. Spalek, and I. Wartenburger. 2013. How pitch accents and focus particles affect the recognition of contextual alternatives. In Proceedings of the 35th Annual Meeting of the Cognitive Science Society, ed. M. Knauff, M. Pauen, N. Sebanz, and I. Wachsmuth, 2434-2440. Austin, TX: Cognitive Science Society.

Gotzner, N., I. Wartenburger, and K. Spalek. 2016. The impact of focus particles on the recognition and rejection of contrastive alternatives. Language and Cognition 8: 59-95.

Grice, M., and S. Baumann. 2002. Deutsche Intonation und GToBI. Linguistische Berichte 191: 267-298.

Grice, M., S. Baumann, and R. Benzmüller. 2005. German intonation in autosegmental-metrical phonology. In Prosodic typology: The phonology of intonation and phrasing, ed. S.-A. Jun, 55-83. Oxford: Oxford University Press.

Grice, M., S. Ritter, H. Niemann, and T.B. Roettger. 2017. Integrating the discreteness and continuity of intonational categories. Journal of Phonetics 64: 90-107.

Grice, P. 1975. Logic and conversation. Syntax and Semantics 3: 41-58.

Grodner, D., N. Klein, K. Carbary, and M. Tanenhaus. 2010. Some, and possibly all, scalar inferences are not delayed: Evidence for immediate pragmatic enrichment. Cognition 116 (1): 42-55.

Groenendijk, J.A.G., and M.J.B. Stokhof. 1984. Studies on the semantics of questions and the pragmatics of answers. PhD thesis, University of Amsterdam.

Horn, L.R. 1976. On the semantic properties of logical operators in English. Bloomington: Indiana University Linguistics Club.

Huang, Y., and J. Snedeker. 2009. Online interpretation of scalar quantifiers: Insight into the semanticspragmatics interface. Cognitive Psychology 58 (3): 376-415.

Husband, E.M., and F. Ferreira. 2016. The role of selection in the comprehension of focus alternatives. Language, Cognition and Neuroscience 31: 217-235.

Ito, K., and S.R. Speer. 2008. Anticipatory effects of intonation: Eye movements during instructed visual search. Journal of Memory and Language 58 (2): 541-573.

Ito, K., S. Speer, and M. Beckman. 2004. Informational status and pitch accent distribution in spontaneous dialogues in English. In Proceedings of Speech Prosody 2004, ed. B. Bel and I. Marlien, 279-282. SProSIG, Aix.

Katz, J., and E. Selkirk. 2011. Contrastive focus vs. discourse-new: Evidence from phonetic prominence in English. Language 87 (4): 771-816.

Kim, C. 2012. Generating alternatives: Interpreting focus in discourse. PhD thesis, University of Rochester.

Krahmer, E., and M. Swerts. 2001. On the alleged existence of contrastive accents. Speech Communication 34: 391-405.

Kripke, S. 2009. Presupposition and anaphora: Remarks on the formulation of the projection problem. Linguistic Inquiry 40 (3): 367-386.

Kügler, F., and A. Gollrad. 2015. Production and perception of contrast: The case of the rise-fall contour in German. Frontiers in Psychology 4: 403. https://doi.org/10.3389/fpsyg.2015.01254.

Kuznetsova, A., P.B. Brockhoff, and R.H.B. Christensen. 2015. Package 'lmertest'. R package version 2(0).

Lee, C. 2008. Contrastive (predicate) topic, intonation, and scalar meanings. Topic and Focus: Crosslinguistic perspectives in meaning and intonation, ed. C. Lee et al., 151-175. Berlin: Springer.

Marty, P.E. 2013. Scalar implicatures: Working memory and a comparison with only. Frontiers in Psychology 4: 403 .

Onea, E., and D. Beaver. 2011. Hungarian focus is not exhausted. In Proceedings of SALT 19, ed. S.I.E. Cormany and D. Lutz, 342-359. Washington, D.C.: LSA.

Pierrehumbert, J. 1980. The phonology and phonetics of English intonation. PhD thesis, MIT.

Pierrehumbert, J., and J. Hirschberg. 1990. The meaning of intonational contours in the interpretation of discourse. In Intentions in Communication, ed. P. Cohen, J. Morgan, and M. Pollack, 271-311. Cambridge, MA: MIT Press.

Rochemont, M. 1986. Focus in generative grammar. Amsterdam: John Benjamins Publishing.

Rooth, M. 1985. Association with focus. PhD thesis, MIT.

Rooth, M. 1992. A theory of focus interpretation. Journal of Semantics 1: 1-42. 
Sauerland, U. 2004. Scalar implicatures in complex sentences. Linguistics and Philosophy 27 (3): 367-391.

Sauerland, U. 2012. The computation of scalar implicatures: Pragmatic, lexical or grammatical? Language and Linguistics Compass 6 (1): 36-49.

Schulz, K., and R. van Rooij. 2006. Pragmatic meaning and non-monotonic reasoning: The case of exhaustive interpretation. Linguistics and Philosophy 29 (2): 205-250.

Schwarz, F. 1015. Presuppositions vs. asserted content in online processing. In Experimental perspectives on presuppositions, ed. F. Schwarz, 89-108. Berlin: Springer.

Schwarz, F., C. Clifton, and L. Frazier. 2008. Strengthening or: Effects of focus and downward entailing contexts on scalar implicatures. In Semantics and Processing (UMOP 37), ed. J. Anderssen et al. Amherst, MA: GLSA.

Selkirk, E. 2002. Contrastive focus vs. presentational focus: Prosodic evidence from right node raising in English. In Proceedings of Speech Prosody 2002, ed. B. Bel and I. Marlin, 643-646. Aix: Université de Provence.

Silverman, K.E., M.E. Beckman, J.F. Pitrelli, M. Ostendorf, C.W. Wightman, P. Price, J. Pierrehumbert, and J. Hirschberg. 1992. ToBI: A standard for labeling English prosody. ICSLP 2: 867-870. Edmonton: University of Alberta

Singh, R., E. Fedorenko, and E. Gibson. 2015. Accommodating presuppositions is inappropriate only in implausible contexts. Cognitive Science 40(3), 607-634. https://doi.org/10.1111/cogs.12260.

Sudhoff, S. 2010. Focus particles and contrast in German. Lingua 120 (6): 1458-1475.

Tomlinson, J., T. Bailey, and L. Bott. 2013. Possibly all of that and then some: Scalar implicatures are understood in two steps. Journal of Memory and Language 69 (1): 18-35.

Tomlinson, J., N. Gotzner, and L. Bott. 2017. Intonation and pragmatic enrichment: How intonation constrains ad-hoc scalar inferences. Language and Speech 60 (2): 200-224.

van Kuppevelt, J. 1996. Inferring from topics. Linguistics and Philosophy 19 (4): 393-443.

van Rooij, R., and K. Schulz. 2004. Exhaustive interpretation of complex sentences. Journal of Logic, Language and Information 13 (4): 491-519.

van Tiel, B., and W. Schaeken. 2017. Processing conversational implicatures: Alternatives and counterfactual reasoning. Cognitive Science 41 (5): 1119-1154.

Wagner, M., and D.G. Watson. 2010. Experimental and theoretical advances in prosody: A review. Language and Cognitive Processes 25 (7-9): 905-945.

Ward, G., and J. Hirschberg. 1985. Implicating uncertainty: The pragmatics of fall-rise intonation. Language 64 (4): 747-776.

Watson, D., C. Gunlogson, and M. Tanenhaus. 2008. Interpreting pitch accents in on-line comprehension: $\mathrm{H}^{*}$ vs. L+H*. Cognitive Science 32: 1232-1244.

Zondervan, A. 2010. Scalar implicatures or focus: An experimental approach. Amsterdam: LOT

Publisher's Note Springer Nature remains neutral with regard to jurisdictional claims in published maps and institutional affiliations. 